\title{
Cyclic testing and numerical modelling of carbon steel and stainless steel tubular bracing members
}

\author{
K.H. Nip, L. Gardner and A.Y. Elghazouli \\ Imperial College London, U.K.
}

\section{INTRODUCTION}

Satisfactory behaviour of structures under severe seismic loading is usually largely dependent on the ability of key components to undergo significant inelastic deformations. In the case of concentrically braced frames, the critical elements are the diagonal bracing members which are expected to experience repeated cycles involving yielding in tension and member buckling in compression. The performance of bracing members depends on various factors, including local slenderness, global slenderness, material yield strength, section shape and end restraint [1]. Due to the difficulty in modelling the non-linearity and cyclic plasticity accurately, numerous experimental studies have been carried out to study the cyclic inelastic behaviour of bracing members.

The interest of researchers in the early days was primarily in the load-displacement hysteretic response of the braces. Models were proposed to predict residual elongation at zero load, loss of compressive strength, the area under the hysteresis loops which represents the amount of energy dissipation, and other key characteristics of the hysteresis loops [2-5]. It was generally concluded [4,5] that global slenderness was the most important parameter influencing the hysteretic behaviour of braces. Slender members lost compressive resistance more rapidly than stocky members, resulting in fewer inelastic response cycles and lower amount of energy dissipation.

More recently, attention has shifted to examination of the factors influencing the fracture life of bracing members. Through experimental testing, both global and local slenderness were found to be important factors in determining fracture life. Tang and Goel [6] proposed one of the first empirical equations for predicting the fracture life of bracing members, which suggests that fracture life is proportional to both the aspect ratio of the cross-section and the global member slenderness but inversely proportional to the square of the local slenderness. However, the validity of this prediction method is limited to bracing members in inverted $\mathrm{V}$ braced frames. Further developments [7-9] in the prediction of fracture life of brace members have utilised this basic proposed equation and generalised the applicability to bracing members in other concentrically braced frame configurations.

A more general relationship was established following a comprehensive survey of the experimental cyclic behaviour of steel bracing members conducted by Tremblay [7], in which buckling resistance, post-buckling resistance in compression, tensile resistance, fracture life and a number of other properties from about 50 members were assessed. Shaback and Brown [8] carried out tests on square hollow section bracing members and calibrated a more sophisticated expression of fracture life, defined as 
the weighted sum of normalised compressive and tensile deformation, in terms of global slenderness, local slenderness, aspect ratio of the cross-section and material yield strength. A similar experiment programme was also conducted by Goggins et al. [9] and examined the influence of several of these parameters for square and rectangular tubular members. Another measure of the ductility of a member - the displacement ductility capacity - defined as the maximum displacement normalised by yield displacement, was expressed in terms of material yield strength, global slenderness and local slenderness respectively in three empirical relationships.

Despite the availability of a number of models for predicting the ductility capacity of braces, there are significant uncertainties in these predictions owing to their semiempirical nature as well as the scatter of test results. Also, the constituent material of the bracing members has not been specifically considered as a factor influencing the ductility of the members. In light of the increasing structural application of stainless steel hollow sections, there is a need to study the behaviour of bracing members of this material under cyclic loading. In particular, it is important to assess the potential benefit of the relatively high tensile ductility and substantial strain hardening of stainless steel. Cyclic material tests have been conducted in a previous study by Nip et al. [10] on structural carbon steel and stainless steel coupons cut from the members tested herein. Suitable strain-life relationships and material cyclic hardening parameters have been calibrated. By introducing the calibrated parameters to finite element models, and utilising the damage prediction method developed previously [11], a reliable means of predicting the fracture life of structural carbon steel and stainless steel bracing members has been established. Such models enable the influence of material properties on cyclic response of structural members to be investigated.

In the current study, cyclic axial tests on carbon steel and stainless steel hollow section members were carried out up to complete fracture, in order to simulate the behaviour of bracing members in concentrically braced frames. The cyclic behaviour of the bracing members in terms of hysteretic loops, displacement ductility and energy dissipation were evaluated. Several sensitivity and parametric studies, using numerical models and a damage prediction method verified against experimental results, were conducted to compare the performance of structural members of different materials over ranges of the full global and local slenderness permitted in the ductile design of earthquake resistant concentrically braced frames [12].

\section{EXPERIMENTAL PROGRAMME}

The objective of the experimental programme was to investigate the cyclic behaviour of bracing members in concentrically braced frames by means of cyclic axial tests. Specimens of hot-rolled carbon steel of Grade S355 J2H [13], cold-formed carbon steel of Grade S235 JRH [14] and cold-formed austenitic stainless steel of Grades EN 1.4301 and 1.4307 [15] were tested. Owing to the similarity in chemical composition and specified mechanical properties, the two stainless steel grades were grouped as the same material in this study, and indeed, exhibited similar behaviour in both material and member tests. 
The basic measured tensile mechanical properties of the three materials are given in Table 1. All the materials had similar yield strength but the stainless steel showed higher ultimate strength and elongation at fracture, which are typical differences between structural carbon steel and austenitic stainless steel. The percentage elongation at fracture was measured over a standard gauge length specified in EN 10002-1 [16]. Testing in the current study involved 16 square and rectangular hollow members of various lengths and section sizes in the three materials, some of which were tested under static loading in compression and bending as part of a comparative study between hot-rolled and cold-formed steel tubular members [17]. The measured geometric properties of the tested sections are given in Table 2, for which the associated symbols are defined in Fig. 1. In Tables 1 and 2, and throughout the paper, specimens are identified by member size (depth $\times$ width $\times$ thickness $\times$ length), material (either carbon steel 'CS' or stainless steel 'SS') and forming process (either hot-rolled 'HR' or cold-formed ' $\mathrm{CF}$ ').

Codes typically impose an upper limit on the global slenderness $\bar{\lambda}$ of bracing members in concentrically braced frames which is specified as 2.0 in EC8 [12]. The global slenderness $\bar{\lambda}$ is defined as

$$
\bar{\lambda}=\sqrt{\mathrm{f}_{\mathrm{y}} \mathrm{A} / \mathrm{N}_{\mathrm{cr}}}
$$

where $\mathrm{f}_{\mathrm{y}}$ is the material yield strength, $A$ is the cross-sectional area, and $\mathrm{N}_{\mathrm{cr}}$ is the elastic critical buckling load. If high dissipative structural behaviour is assumed in the design, cross-sections of bracing members are required to be Class 1 . The local slenderness of a cross-section, upon which the cross-section class is determined, is defined as $b / t \varepsilon$ where $b$ is the flat width of the wider face of the section, $t$ is the thickness of the section and $\varepsilon=\sqrt{235 / \mathrm{f}_{\mathrm{y}}}$. In the current experimental and parametric studies, all specimens conform to the $\bar{\lambda}<2.0$ requirement. All cross-sections are deemed as Class 1 according to EC3 Part 1-3 [18] and the new slenderness limits recently proposed for stainless steel sections by Gardner and Theofanous [19], though the most slender stainless steel sections in the experimental and parametric studies, respectively, are Class 3 according to EC3 Part 1-4 [20]. The revised slenderness limits for stainless steel sections [19] are based on a considerably larger pool of experimental data than was available at the time of preparation of EC3 Part 1-4 [20], and are thus considered more representative of observed physical behaviour.

Specimens were tested under cyclic axial loading in an internal reaction frame as shown in Fig. 2. Displacements and rotations were restrained at both ends of the members, other than axial displacement at the loaded end, which was controlled by a $100 \mathrm{~T}$ Instron hydraulic actuator. A transducer was used to measure any displacement at the unloaded end of the member so that the flexibility of the test rig could be eliminated when the test data were processed. Strain gauges were placed at the centre of each flat face and at each corner at the mid-length of the specimens in order to measure the distribution of strain across the section during buckling. Two draw-wire transducers were attached to the specimens to measure the lateral deflection at midlength in the vertical and horizontal directions (Fig. 3). In order to prevent premature fracture at the welded end plates, a stiffener plate was inserted at each end of the specimens to provide an adequate length of weld between the specimen and the end plates. The end plates were bolted to the actuator and to the reaction frame. Details of the end plate connections are shown in Fig. 4. The end connections were designed to 
be fully fixed and minimal end rotation was generally observed during testing; the effective column lengths were therefore assumed to be half of the length of the specimens.

The applied axial displacement history followed the recommendations of ECCS [21], i.e. one cycle at each level of $0.25,0.5,0.75$ and $1.0 \Delta_{y}$, followed by three cycles at each level of $2,4,6,8 \Delta_{\mathrm{y}}$, etc., where $\Delta_{\mathrm{y}}$ is the estimated axial yield displacement. In the current study, tensile coupons of the materials at the flat faces and corner areas were tested. Typical stress-strain curves are given in Figs 5 and 6 . The yield strains of flat and corner materials were weighted according to their proportions of area in the cross-section to give the yield strain of a section. The yield displacement of each specimen was then determined as the product of the length of the member and the weighted yield strain of the cross-section. For the cold-formed carbon steel and stainless steel sections, the strain at the $0.2 \%$ proof stress was taken as the yield strain. The displacement was applied at a strain rate of $3 \times 10^{-4} \mathrm{~s}^{-1}$ which is within the recommended range for quasi-static testing [22].

\section{TEST RESULTS}

A summary of the test specimens and results, including applied yield displacement, local and global slenderness, number of cycles before the occurrence of global buckling, local buckling and corner fracture, together with the displacement ductility, is given in Table 3. A more detailed description of test results is provided below.

\subsection{Hysteretic response}

Specimens typically underwent elastic deformation in the first few cycles. Global lateral buckling was generally initiated when the applied displacement was in the proximity of the yield displacement. At this stage in the cyclic loading regime, the deformed shape of the specimens resembled that of elastic buckling (Fig. 7). As expected, the stockier members buckled one or two cycles after the relatively slender specimens. Upon reloading in tension, the specimens were straightened but there always remained a small residual lateral deflection. The three RHS specimens exhibited horizontal deflections only (i.e. buckling about the weaker axis), though the longer RHS specimens also showed small vertical deflections (i.e. a degree of buckling about the stronger axis). All short SHS specimens deflected in either the horizontal or vertical directions, though Specimen $60 \times 60 \times 3 \times 1250$-SS-CF showed deflections in both directions, though one was dominant. Horizontal and vertical components of deflection were observed, to some degree, in all medium-length and long specimens. As the applied displacement increased, local buckling occurred at mid-length and, in some specimens, close to the end stiffeners. Plastic hinges formed at those locations, which resulted in the mechanism shown in Fig. 8. More pronounced local deformation was observed at the mid-length of the member than at the member ends due to the larger rotation.

Measurements of mid-length lateral deflections (i.e. the magnitude of the vertical and horizontal components) for the short, medium and long cold-formed stainless steel $60 \times 40 \times 3$ specimens are shown in Fig. 9, along with the predictions of lateral 
deflection according to Tremblay [7]. The predictions are based on the deformed geometry of the specimens after the formation of a plastic mechanism, which leads to longer specimens having larger lateral deflections at a given applied axial displacement. The measured deflections gradually increased as larger axial displacements were applied and as the plastic mechanism formed but only increased modestly during cycles at the same applied axial displacements. The predictive model considers permanent elongation due to yielding, but not axial shortening, so the predictions provide a conservative estimation of the lateral deflections. In Fig. 10, the measured mid-length lateral deflections for three specimens with similar global slenderness but different local slenderness and materials are compared. The predicted values given by Tremblay [7] for the three specimens are very close and have therefore been represented by a single curve. However, the results show that the $50 \times 50 \times 3 \times 1250$-SS-CF has a smaller lateral deflection than that of the hot-rolled and cold-formed carbon steel specimens. It may be seen that, as far as lateral deflections are concerned, local slenderness, material properties, the length of the specimens and the deformed shape, i.e. 'elastic buckling' or 'plastic hinge mechanism' are all influential factors.

Typical load-displacement hysteretic curves are given for all test specimens in Figs 11-13. Absolute values of load and displacement are used instead of normalised ones to facilitate comparison with analysis by other researchers. Displacement can be readily converted to ductility by using values of yield displacement in Table 3 . In the following sections, the terms tensile loading half cycle and compressive loading half cycle are used as indicated in Fig. 11(a). Comparison between typical loaddisplacement hysteretic loops for bracing members of the three materials with similar global slenderness and local slenderness can be made by considering the graphs of $60 \times 60 \times 3 \times 2050$-CS-HR, $60 \times 60 \times 3 \times 2050-$ CS-CF, $50 \times 50 \times 3 \times 1250-$ SS-CF in Figs $11(\mathrm{a})$, 12(a) and 13(h). Cyclic hardening is most pronounced for the cold-formed stainless steel specimen, which is manifested by high maximum tensile resistance in Fig. 13(h). Furthermore, during the first cycle at each displacement amplitude, a non-zero tangent stiffness is maintained throughout almost the entire tensile half-cycle. In contrast, the tensile resistance of the carbon steel specimens reaches a plateau earlier in the corresponding cycles. In the second and third tensile half-cycles at $\pm 4 \Delta_{y}$, for example, the stainless steel specimen maintains a high tangent stiffness while the carbon steel specimens show a concave curve in the tensile loading half cycle and low tangent stiffness at zero applied displacement. During the compressive loading half cycles, nonlinearity initiates earlier for the stainless steel member but the deterioration of compressive resistance is slower after buckling has occurred. This is reflected in Fig. 14 which shows the change in maximum compressive resistance, $F_{y}$, at various applied displacements. The stainless steel specimen has a lower compressive resistance in the initial cycles. As the test progresses, the stainless steel specimen gradually develops higher compressive resistance due to the more substantial cyclic hardening. It achieves the highest resistance at a ductility of 4.

The normalised initial buckling loads observed in the experiments are plotted against global slenderness and are compared with the design resistance, $\mathrm{F}_{\mathrm{b}}$, given in Eurocode 3 (Fig.15). Cross-sectional area and material yield strength are represented by A and $\mathrm{f}_{\mathrm{y}}$, respectively, in the figure. Buckling 'curve a' and 'curve c' in EC3 Part 1-1 [18] are prescribed for hot-rolled and cold-formed carbon steel hollow sections respectively. The buckling curve for stainless steel hollow sections provided in EC3 
Part 1-4 [20] has a plateau length $\bar{\lambda}_{0}=0.4$ and an imperfection factor $\alpha=0.49$. Although the design curves have been derived from quasi-static test results, they offer satisfactory prediction of the buckling loads of the test specimens which have been preceded by a number of small amplitude load cycles. The stainless steel curve gives the best agreement with the tests while the hot-rolled and cold-formed carbon steel data points are all above their corresponding curves.

The compressive resistance in subsequent cycles reduces due to the accumulated elongation and residual lateral deformation of the specimens. In order to evaluate the minimum post-buckling resistance of bracing members at certain ductility level, which is a critical loading scenario for determining the forces developed in other frame members [1], various predictive equations have been proposed. According to AISC [23], the design post-buckling compressive strength is $30 \%$ of the initial buckling strength regardless of global slenderness and applied displacement. Tremblay [7] has collected test results with symmetrical loading histories and derived expressions for minimum post-buckling resistance at compressive displacements of $2 \Delta_{\mathrm{y}}, 3 \Delta_{\mathrm{y}}$ and $5 \Delta_{\mathrm{y}}$ respectively in terms of global slenderness. Similarly, Remennikov and Walpole [24] have proposed an empirical relationship for post-buckling resistance at a compressive displacement of $5 \Delta_{\mathrm{y}}$ for braces with global slenderness less than 1.27.

The symmetric loading regime employed in the present study simulates braces in frames with similar level of expected peak ductility in tension and compression. In light of this, the minimum post-buckling resistance is taken as the load in the test member when the target compression ductility level is reached for the first time after the specimen has experienced the same ductility level in tension. Minimum postbuckling resistances of the test specimens at compression displacements equal to $2 \Delta_{\mathrm{y}}$ and $4 \Delta_{\mathrm{y}}$ are shown in Figs 16 and 17 respectively, along with predictive curves [7, 23, 24]. As suggested in a previous study [7], the predictions of resistance at compressive displacements equal to $4 \Delta_{\mathrm{y}}$ have been obtained by linear interpolation of the predictions at displacements equal to $3 \Delta_{\mathrm{y}}$ and $5 \Delta_{\mathrm{y}}$. The behaviour of the specimens of the three materials follows a similar trend, with stainless steel specimens retaining slightly higher post-buckling resistance. Tremblay's [7] expressions provide good estimations of the post-buckling resistance for stainless steel specimens at displacements equal to $2 \Delta_{\mathrm{y}}$ and $4 \Delta_{\mathrm{y}}$, despite the expressions having been derived from results of carbon steel specimens. The curve from AISC [23] also gives satisfactory predictions for members with intermediate and high global slenderness at displacements equal to $4 \Delta_{\mathrm{y}}$. However, Remennikov and Walpole [24] overestimate the post-buckling resistance of the specimens over much of the range of global slenderness for which the expression is intended.

The shape of the hysteretic loops also affects an important indicator of the performance of a bracing member - energy dissipation. In order to provide a normalised comparison of energy dissipation, hysteretic energy, W, can be normalised by yield load and yield displacement of the specimens. Although the stainless steel specimens exhibit higher tensile and compressive resistances than the carbon steel specimens, the areas under the hysteretic loops of specimens of the three materials are similar. Fig. 18 shows the accumulation of hysteretic energy dissipation of specimens with similar slenderness in the three materials. The sharper increase in energy dissipation of the stainless steel specimen in the last two cycles relates to its ability to 
maintain high stiffness at $\pm 4 \Delta_{y}$, which leads to larger hysteretic loops. Fig. 19 shows the normalised energy dissipation during the $8^{\text {th }}$ cycle, which is the cycle with the largest amount of energy dissipation for most specimens. It reveals a trend of decreasing energy dissipation with increasing global slenderness but there is no obvious distinction between the three materials.

\subsection{Fracture life}

Once local buckling occurs, high stresses and strains develop in the corner areas which offer higher axial stiffness than the flat faces. Strain localisation in the corner areas leads to crack initiation after a few cycles of successive inelastic buckling and tensile yielding. These cracks grow into larger opening and propagate quickly around the cross-section under tensile loading. This sequence of events was observed in all test specimens. Tests were continued until complete fracture of the specimens. Figs 20(a)-(c) show the onset of local buckling, formation of small openings at the corners and complete fracture of specimen $60 \times 40 \times 3 \times 1250-\mathrm{SS}-\mathrm{CF}$, respectively.

13 out of 16 test specimens fractured at the mid-length where the rotation was the largest. However, welding at the member ends introduces defects and can affect the ductility of the material in the region of the stiffeners. Specimens $40 \times 40 \times 4 \times 2050$-CS$\mathrm{CF}$ and $40 \times 40 \times 3 \times 2050-\mathrm{CS}-\mathrm{CF}$ fractured in the heat affected zone adjacent to the stiffeners while Specimen $60 \times 40 \times 3 \times 2850$-SS-CF failed at the weld. Although small cracks appeared in the weld of Specimens $40 \times 40 \times 3 \times 2050$-CS-HR, $40 \times 40 \times 3 \times 1250$ CS-CF and $60 \times 60 \times 3 \times 2050-S S-C F$, final fracture occurred at mid-length.

Complete fracture of a specimen is a common definition of failure but is not always appropriate for signalling the significant loss of resistance of a member. Once an opening is formed, it grows quickly and the reduction in cross-sectional area weakens the specimen. Some specimens survived a number of additional cycles following corner opening by relying on a small fraction of the cross-section remaining intact; however, in practice, such a bracing member will no longer be capable of providing effective lateral stiffness to the frame. Therefore, in this study, the number of cycles to failure has been defined as the cycle when small cracks at the corner grow into an opening, which can often be indentified in a load-displacement hysteresis curve by a sudden drop in load.

Table 3 summarises the numbers of cycles at which global buckling, local buckling and initiation of an opening occurred. An alternative measurement of deformation capacity, the displacement ductility, is also presented in the table. This is defined as the maximum displacement to which a specimen has been subjected before failure, divided by its yield displacement. The majority of the specimens showed local buckling at around the eighth cycle when the maximum strain in the flat faces reached around $4 \%$ due to combined axial and bending deformations. The specimens which buckled locally at the eighth cycle then failed soon afterwards at a displacement ductility of 4. Some specimens, which were either of low local slenderness or high global slenderness, showed higher displacement ductility. The influence of these two slenderness parameters can be examined more clearly with data from other experimental programmes and numerical studies. 
In order to study the performance of braces outside the tested range, a numerical modelling programme was undertaken. Detailed three-dimensional finite element (FE) models of bracing members have been developed. FE modelling was utilised instead of phenomenological models since they are able to simulate not only global behaviour, but also local buckling and deformation of the cross-section, which are critical for predicting fracture.

The general purpose finite element package ABAQUS [25] was used to develop models firstly to replicate the behaviour of tested SHS and RHS braces. The models were subjected to cyclic axial displacements with large plastic deformation within non-linear analyses. Two lines of symmetry were utilised in the models such that only one quarter of the members were required to be modelled, as depicted in Fig. 21. Output from the models was used in conjunction with a strain-based damage prediction method to determine the fracture life of the braces. The numerical results were initially validated against tests, after which, a series of parametric studies was performed.

\subsection{Element type and mesh size}

The 4-node doubly curved general-purpose shell element with reduced integration, designated S4R [25] has been employed throughout the study. This element allows transverse shear deformation and can be used for thick or thin shell applications. It has been successfully used in previous studies for modelling hollow section columns and produced accurate results for compressive resistance and failure modes [26, 27].

Strain outputs from the models were found to be sensitive to mesh size. In order to improve computational efficiency, varying mesh densities were employed in different areas of the models. Refined meshes were used only in areas where local buckling was anticipated, i.e. at the mid-length and ends of the members, since all braces were fixed-ended. The size of the elements in the refined mesh at mid-length was determined by a convergence study [11]. Strain outputs were extracted only from the elements in the region of the mid-length of the members, since this is where fracture was observed in the experiments. The fine mesh at the end of the braces was required to capture the location and shape of local buckling accurately but no strain outputs from that part were used for predicting fracture. The demand of the fineness of mesh at each end of the braces was lower than at mid-length and therefore a coarser mesh was used.

The extent of the refined mesh in the longitudinal direction was set to 1.5 times the dimension of the larger face of the section. This ensured that the refined area was sufficiently large to accommodate the half wavelength of the locally buckled shape, which was approximately equal to the dimension of the larger face of the section. Since local buckling may occur within the length of the stiffeners or beyond it, a refined mesh was applied to the stiffened region and extended 1.5 times the dimension of the larger face of the section.

\subsection{Material modelling}


A material model capable of simulating cyclic material properties such as the Baushinger effect and expansion of the elastic material range was needed to represent the large plastic strains and load reversals. The nonlinear isotropic/kinematic hardening model [25] was adopted in the FE models in the current study. A series of strain-controlled fully-reversed cyclic axial tests on coupons cut from the test specimens was carried out to calibrate the material model. The values of the parameters have been determined in a previous study [10].

The strength enhancement in the corner regions of the cold-formed sections was also considered. The strength enhancement were assumed to extend beyond the corner to a distance equal to the material thickness for the cold-formed carbon steel models [28] and two times the material thickness for the cold-formed stainless steel models $[29,30]$. Homogeneous material properties around the section were assumed for the hot-rolled carbon steel models.

\subsection{Initial geometric imperfections}

All structural members contain initial geometric imperfections. These imperfections trigger out-of-plane deflections at stresses below the theoretical critical buckling values. In this study, both global and local initial geometric imperfections were incorporated into the numerical models to assess their influence. The amplitude of global imperfection was measured for each of the test specimens in two perpendicular directions. The observed amplitude of global imperfection was applied in the direction of global buckling in the models by introducing an equivalent load at mid-length.

Local geometric imperfections comprising longitudinal sinusoidal waves with halfwavelength equal to the width of the section and compatible sinusoidal half-waves across the section faces were introduced into the numerical models. The imperfections were incorporated into the models by defining nodes directly in their imperfect configuration. The amplitudes of the initial imperfections of stainless steel specimens were taken from the predictive formula proposed by Dawson and Walker [31] and calibrated by Gardner and Nethercot [29] as given by Eq. (2):

$$
\omega_{0} / \mathrm{t}=0.023\left(\mathrm{f}_{\mathrm{y}} / \sigma_{\mathrm{cr}}\right)
$$

where $\omega_{0}$ is the initial imperfection amplitude, $t$ is the plate thickness, $f_{y}$ is the material yield stress and $\sigma_{\mathrm{cr}}$ is the plate critical buckling stress. Gardner et al. [17] measured the local imperfections in the specimens used in this study and other similar specimens. A least-squares regression analysis of the measured imperfection data for cold-formed and hot-rolled hollow sections resulted in the proposal of the predictive expressions given by Eqs (3) and (4) respectively. These are based on a second model by Dawson and Walker [31] in which the ratio of $\mathrm{f}_{\mathrm{y}} / \sigma_{\mathrm{cr}}$ is raised to the power of 0.5 , such that:

$$
\begin{aligned}
& \omega_{0} / t=0.034\left(f_{y} / \sigma_{c r}\right)^{0.5} \\
& \omega_{0} / t=0.028\left(f_{y} / \sigma_{c r}\right)^{0.5}
\end{aligned}
$$

\subsection{Damage prediction}


As fracture was not explicitly simulated in the models, a strain-based damage prediction method was adopted. The adopted procedure for predicting damage required the monitoring of strains during each cycle of loading. Average strains over an area covering the corner and one-eighth of the buckling wavelength were used to predict damage and calculate fatigue life. Details of the procedures and FE models have been reported previously [11]. The strain-life relationship for each of the materials tested in the current study was established though ultra low cycle fatigue material testing [10].

\subsection{Verification}

Prior to performing parametric studies, the FE models were verified against the cyclic axial tests carried out in the present study and further tests from the literature. Boundary conditions were applied to the numerical models to represent the fixed end conditions of the test specimens; the end stiffeners were also modelled. All degrees of freedom of nodes at both ends of the members were restrained, except for the axial displacement at the loaded end.

Hysteresis curves from selected FE simulations and corresponding tests on specimens of the three materials are shown in Figs 22(a)-(c). The comparison shows that the FE models are capable of simulating the hysteretic behaviour well for all three materials. It may be seen that the drop in compressive resistance after buckling is more pronounced in the FE models than in the tests and that load continues to rise until the maximum tensile displacement has been reached in the carbon steel models, as opposed to the plateau seen in the experiments. These discrepancies are attributed to the limited number of parameters (four) in the material model which can lead to inaccuracies in fully capturing the precise material response [10]. Three extra test results from Goggins et al. [9] and Walpole [32] have also been employed to verify the applicability of the current models to other specimens and loading regimes, as discussed below.

A comparison between the number of cycles to failure and predictions from the FE models is presented in Table 4. The agreement between test and FE results is good with only a few exceptions which may be due to the premature cracking in the weld regions. These cracks reduce the rotational stiffness at the ends of the specimens and increase their effective length, which lessens the rotation at the mid-length. The discrepancy between the results of Goggins et al. [9] and the numerical predictions may be due to the assumptions that had to be made on the material properties.

A crucial criterion for accurate prediction of fracture is reproducing the strain distribution correctly in the FE models. The FE and experimental strain measurements at various stages of the cyclic axial test on Specimen $60 \times 60 \times 3 \times 2850-\mathrm{SS}-\mathrm{CF}$ are presented in Figs 23(a)-(c). The FE strain output has been extracted from the same locations as the strain gauges (Fig. 3). The FE models capture the variation of strain across the section accurately and are capable of predicting the high strains at the corner areas which eventually lead to fracture. The only significant discrepancy between test measurements and FE arises at the corner areas after local buckling has occurred (Fig. 23(c)). This discrepancy is believed to be due to the fact that the actual deformations in the tests have exceeded the working range of the strain gauges and they are thus unreliable. Nevertheless, it is evident that the FE models can predict the 
buckling and failure of SHS and RHS braces under cyclic loading, although their level of accuracy for different materials and configurations are to be identified in Section 5.

A sensitivity study has been conducted to assess the response of the models to variation in global and local imperfections. The amplitude of the local imperfection was varied from $t / 10$ to $t / 1000$ while that of the global imperfection was varied from $\mathrm{L} / 100$ to $\mathrm{L} / 10000$. The study showed that larger amplitudes of both global and local imperfections cause earlier local buckling but the effect on fracture is small. It was found that varying the amplitude of imperfection by a factor of 100 generally only resulted in a difference of 2 cycles or less to fracture.

\section{PARAMETRIC STUDIES}

Parametric studies were conducted to compare the performance of members of the three materials, particularly in the aspects of number of cycles to failure, energy dissipation and tangent stiffness. In this study, 16 models were considered for each material. These were $60 \times 60 \mathrm{~mm}$ square hollow sections with thicknesses of $2.5 \mathrm{~mm}$, $3.0 \mathrm{~mm}, 4.0 \mathrm{~mm}$ and $6.0 \mathrm{~mm}$. The member lengths were $1500 \mathrm{~mm}, 2500 \mathrm{~mm}, 3500$ $\mathrm{mm}$ and $5000 \mathrm{~mm}$.

In order to ensure a consistent comparison between the materials, the yield strengths of the three materials were set equal to one another, while the cyclic material parameters reflected their particular characteristics in terms of cyclic hardening. A global imperfection of L/1500 and local imperfection with amplitudes obtained from Eqs (2)-(4) were incorporated in the models. In some cases, slightly larger local imperfections were applied to overcome numerical difficulties, but the sensitivity study showed that the effect of such changes was negligible.

Similar to the experimental specimens, all models remained elastic in the first few cycles, followed by global buckling and inelastic deformation. Local buckling was observed at the mid-length and, to a lesser extent, at the ends. Fracture was predicted to occur at the mid-length where the deformation was the largest, although a few exceptional cases showed that fracture occurred at the area of local buckling at the ends. Among the models of the same material, the variation of number of cycles to fracture and energy dissipation with global and local slenderness was similar to that observed in previous studies $[6,7,9]$ - in general, the number of cycles to fracture increases with increasing global slenderness and decreases with increasing local slenderness. Braces with low global slenderness dissipate more energy than slender members of the same cross-section. Details of these trends and explanation of the behaviour are discussed by Nip et al. [11]. The following sections focus specifically on comparisons between the three materials.

\subsection{Fracture life}

The number of cycles to failure for each specimen is plotted against global slenderness in Figs 24(a)-(d). All stainless steel models exhibit a larger number of cycles to fracture than their carbon steel counterparts. Except for the most slender cross-sections, the number of cycles to fracture increases with global slenderness, as 
does the difference in fracture life between the stainless steel and carbon steel members. The plots also show a smaller but consistent difference between hot-rolled and cold-formed carbon steel, with the former exhibiting slightly large number of cycles for most of the slenderness ranges. The same set of data was reorganised and plotted against local slenderness in Figs 25(a)-(d). A similar trend can be observed upon variation of local slenderness. The number of cycles to fracture increases with decreasing local slenderness, and at low slenderness the difference in fracture life between the stainless steel and carbon steel members is greatest, apart from the most stocky members.

Empirical equations have been proposed to predict the fracture life of braces from test results on cold-formed carbon steel bracing members and occasionally together with hot-rolled carbon steel bracing members. Although many of these equations have not been specifically developed for hot-rolled carbon steel and cold-formed stainless steel members, these equations have been compared with the experimental and FE results of specimens of the three materials from the current study, in addition to the data available in the literature [9, 32]. Goggins et al. [9] carried out cyclic tests on coldformed carbon steel specimens. The end connection details and loading history were the same as those employed in present study. From Walpole's study [32], the test result for a cold-formed specimen with fixed end conditions has examined in the current study, while results for other specimens with pinned end are not considered. Comparison with these additional experiments [9, 32], allows the applicability of the equations to more materials and over a larger range of slenderness to be assessed.

A cumulative measure of ductility takes into account the characteristics of the loading history prior to failure. Shaback and Brown define the accumulated fracture ductility $\left(\mu_{\Delta, f}\right)$ as the weighted sum of normalised compressive $\left(\mu_{\Delta, 1}\right)$ and tensile deformation $\left(\mu_{\Delta, 2}\right)[8]$ :

$$
\mu_{\Delta, \mathrm{f}}=\sum\left(0.1 \mu_{\Delta, 1}+\mu_{\Delta, 2}\right)
$$

Predictive equations have been calibrated by tests on cold-formed carbon steel square hollow section bracing members $[8,33]$ and are given as:

$$
\begin{array}{ll}
\mu_{\Delta, \mathrm{f}}=\mathrm{C}_{\mathrm{s}} \frac{\left(350 / \mathrm{f}_{\mathrm{y}}\right)^{-3.5}}{[(\mathrm{~b}-2 \mathrm{t}) / \mathrm{t}]^{1.2}}\left(\frac{4(\mathrm{~b} / \mathrm{d})-0.5}{5}\right)^{0.55}(70)^{2} & \text { for } \frac{\mathrm{KL}}{\mathrm{r}}<70 \\
\mu_{\Delta, \mathrm{f}}=C_{s} \frac{\left(350 / f_{y}\right)^{-3.5}}{[(b-2 t) / t]^{1.2}}\left(\frac{4(b / d)-0.5}{5}\right)^{0.55}\left(\frac{K L}{r}\right)^{2} & \text { for } \frac{\mathrm{KL}}{\mathrm{r}}>70
\end{array}
$$

where $\mathrm{C}_{\mathrm{s}}$ is an empirical constant taken as $0.065, \mathrm{~K}$ is the effective length factor, $\mathrm{b}$ is the longer face of the cross-section, $d$ is the shorter face of the cross-section, $t$ is the thickness of cross-section, $r$ is the radius of gyration and $f_{y}$ is the material yield strength in $\mathrm{N} / \mathrm{mm}^{2}$. The predicted values of accumulated fracture ductility are generally similar to the experimental and FE results only with some exceptions for specimens exhibiting large accumulated fracture ductility. However, this prediction method tends to overestimate the ductility of cold-formed stainless steel experimental specimens and underestimates the corresponding FE specimens (Fig. 26). This contradiction indicates a high sensitivity of accumulated fracture ductility to the shape of the hysteretic loops. 
A prediction method independent of the shape of hysteretic loops is more desirable because it gives the ductility of bracing members without requiring detailed knowledge of the load-displacement response. Such a relationship between displacement ductility $\left(\mu_{\Delta}\right)$ and global slenderness has been established from tests conducted with a number of loading histories [7]:

$$
\mu_{\Delta}=2.3+8.3 \bar{\lambda}
$$

Goggins et al. [9] noted that both global slenderness and local slenderness affected the displacement ductility of bracing members. Eq. (9) was re-calibrated with their test data and a new relationship expressing displacement ductility in terms of local slenderness was proposed (Eq. (10)):

$$
\begin{gathered}
\mu_{\Delta}=-0.7+26.2 \bar{\lambda} \\
\mu_{\Delta}=29.1-1.07(\mathrm{~b} / \mathrm{t})
\end{gathered}
$$

A comparison between these equations and results from the current study shows that these relationships generally overestimate the displacement ductility and do not fit the derived test data over the full range of global and local slenderness (Table 5).

In light of the co-existing influence of global slenderness and local slenderness, Tremblay et al. [34] proposed an expression for rotation at fracture, $\theta_{\mathrm{f}}$, in terms of both slenderness parameters:

$$
\theta_{\mathrm{f}}=0.091\left(\frac{\mathrm{b}}{\mathrm{t}} \frac{\mathrm{d}}{\mathrm{t}}\right)^{-0.1}\left(\frac{\mathrm{KL}}{\mathrm{r}}\right)^{0.3}
$$

where $\mathrm{b} / \mathrm{t}$ is the section width-to-thickness ratio, $\mathrm{d} / \mathrm{t}$ is the section depth-to-thickness ratio, $\mathrm{KL}$ is the effective length and $\mathrm{r}$ is the radius of gyration. In cases where rotation at fracture has not been measured, it has to be obtained from the plastic hinge model [7], which has been shown to overestimate the lateral deflections of the braces in the previous section of this paper. Consequently, although Eq. (11) generally provides better predictions than Eqs (7)-(10), it tends to underestimate the rotation at fracture implied from the experiments. (Fig. 27)

Displacement ductility can be easily measured and has been reported in most experimental programmes. Predictive expressions for displacement ductility which address the co-existing influence of global slenderness and local slenderness for braces of each material are therefore proposed based on the results of this study as follows:

$\begin{array}{ll}\text { Hot-rolled carbon steel: } & \mu_{\Delta}=3.69+6.97 \bar{\lambda}-0.05(\mathrm{~b} / \mathrm{t} \varepsilon)-0.19(\bar{\lambda})(\mathrm{b} / \mathrm{t} \varepsilon) \\ \text { Cold-formed carbon steel: } & \mu_{\Delta}=6.45+2.28 \bar{\lambda}-0.11(\mathrm{~b} / \mathrm{t} \varepsilon)-0.06(\bar{\lambda})(\mathrm{b} / \mathrm{t} \varepsilon) \\ \text { Cold-formed stainless steel: } & \mu_{\Delta}=-3.42+19.86 \bar{\lambda}+0.21(\mathrm{~b} / \mathrm{t} \varepsilon)-0.64(\bar{\lambda})(\mathrm{b} / \mathrm{t} \varepsilon)\end{array}$

Table 5 shows the comparison between the predicted values and the FE or experimental results for Eqs (8)-(10) and (12)-(14), which indicates that the new expressions improve the predictions of displacement ductility and that separate expressions for each material are necessary. The new relationships predict the displacement ductility accurately for members with a range of ductilities (Fig. 28).

The trends of displacement ductility predicted by Eqs (12)-(14) are given in Fig. 29. Members with a cross-section slenderness $b / t \varepsilon=30$, which is close to the upper limit 
of Class 1 cross-sections, exhibit a relatively low level of ductility regardless of the global slenderness or the constituent material. Stainless steel members with stocky cross-sections and high global slenderness show higher ductility than their carbon steel counterparts. The hot-rolled carbon steel bracing members show higher ductility in comparison with the cold-formed carbon steel members, particularly for relatively high $\bar{\lambda}$ and low $\mathrm{b} / \mathrm{t} \varepsilon$. This difference diminishes however at low $\bar{\lambda}$ values and high $\mathrm{b} / \mathrm{t} \varepsilon$ proportions.

Since strain localisation due to local buckling is a significant contributor to the initiation of fracture, the difference in number of cycles to failure between different members can be explained by examining the factors that influence local buckling. The occurrence of local buckling of a plated element of a hollow section member depends on the tangent stiffness of the material, which changes at different stages of loading. Figs 30(a) and (b) show a comparison of the stress-strain hysteretic behaviour of the three materials subjected to cyclic axial loading at strain amplitudes of $\pm 1 \%$ and $\pm 3 \%$ respectively. These tests have been carried out on coupons cut from the flat faces of hollow section members examined in a complementary study [10]. In Fig. 31(a), coldformed stainless steel shows higher compressive stiffness than hot-rolled and coldformed carbon steel except for some points on the elastic unloading branch after load reversal. In Fig. 31(b), cold-formed stainless steel has similar compressive stiffness to hot-rolled carbon steel while cold-formed carbon steel has lower stiffness.

For slender members and all members with stocky cross-sections, stainless steel exhibited a higher number of cycles to fracture than carbon steel. Strains experienced at the critical cross-sections of these members following global buckling were in the region of $\pm 1 \%$. As shown in Fig. 31(a), the tangent compressive stiffness at zero strain of cold-formed stainless steel is approximately $54000 \mathrm{~N} / \mathrm{mm}^{2}$, which is twice of the value for cold-formed carbon steel. Stainless steel material maintains higher compressive stiffness at this strain amplitude and therefore delays local buckling and hence fracture. The difference between stainless steel and carbon steel is greatest for members with high global slenderness or low local slenderness. Strains in the critical regions of members with low global slenderness or high local slenderness are higher, at around $\pm 3 \%$. At this strain amplitude, the stiffness of the three materials is similarly low, as shown in Fig. 31(b) where the tangent compressive stiffness at zero strain of the three materials is below $1 \%$ of the elastic stiffness, and hence local buckling is more readily triggered, resulting in a similar number of cycles to failure for all three materials.

\subsection{Energy dissipation and hysteretic loops}

Normalised hysteretic energy is obtained by calculating the area under loaddisplacement hysteretic loops with normalisation by yield load and yield displacement, respectively. It was found that the areas under the hysteretic loops of models of the whole ranges of global and local slendernesses of the three materials were similar for all three materials and over the investigated ranges of both local and global slenderness; hence the accumulated energy dissipation of the three materials follows a similar trend (Fig. 32). However, the stainless steel members with stocky crosssections or high global slenderness withstand significantly more cycles than their carbon steel counterparts and thus the total energy dissipation to fracture is higher. 
The same also applies, but to a lesser extent, to the higher energy dissipation in the hot-rolled carbon steel members in comparison with the cold-formed carbon steel specimens. This is attributed to the reduced ductility at the corners caused by the coldforming process.

The shapes of the hysteretic loops of the models of the three materials are different although their areas are approximately the same. Figs 33(a) and 33(b) show the hysteretic loops of the $8^{\text {th }}$ and $9^{\text {th }}$ cycle for the $60 \times 60 \times 6 \times 3500$ models of the three materials respectively. These represent the shapes of typical hysteretic loops during the first and subsequent cycles of loading at a certain applied displacement. The stainless steel specimen develops higher tensile resistance in both cycles due to cyclic hardening of the material. Figs 34(a) and 34(b) show the tangent tensile stiffness of the braces during these two cycles respectively. In the $8^{\text {th }}$ cycle, the peak tangent tensile stiffness reached by the three specimens is similar but the stainless specimen maintains a higher tangent stiffness while the two carbon steel specimens exhibit a load plateau at large tensile displacement. During the next cycle, the peak tangent stiffness of the stainless steel specimen does not deteriorate as much as that of the carbon steel specimens. Also, the peak tangent stiffness develops at a smaller tensile displacement than the carbon steel specimens. These are crucial characteristics that influence the design of concentrically braced frames, since bracing members acting in tension are the main source of stiffness in concentrically braced frames.

\section{CONCLUSIONS}

A total of 16 square and rectangular hollow section members of three materials - hotrolled carbon steel, cold-formed carbon steel and cold-formed stainless steel - were tested under cyclic axial loading. The full hysteretic response and key test results from all tests have been reported. Despite a significant difference in monotonic material properties, in particular tensile ductility and pronounced strain hardening, member behaviour was found to differ to a lesser extent. Nevertheless, stainless steel specimens showed higher tensile and compressive resistance and maintained higher tensile stiffness, when compared to carbon steel specimens with similar characteristics and slenderness.

FE models, verified against the experimental results from the current study and two other research programmes, were used in conjunction with a strain-based damage prediction method to conduct a parametric study. Stainless steel members were found to be capable of sustaining more cycles of loading than carbon steel members prior to fracture, especially for stocky (low b/t) sections and members with high global slenderness. In comparison with cold-formed carbon steel, hot-rolled specimens were relatively more ductile particularly for high global slenderness and low local slenderness. The empirical expressions, derived from carbon steel test data, for predicting the buckling resistance, compressive post-buckling resistance and midlength lateral deflection have been found to be generally applicable to cold-formed stainless steel members. However, due to the difference in member ductility and inclusion of data of specimens of a larger range of slenderness, previous relationships between member ductility and slenderness do not give satisfactory predictions of the experimental and FE results obtained in the current study. Expressions of 
displacement ductility in terms of both global slenderness and local slenderness have been calibrated for braces of each material. These relationships accurately reflect the influence of slenderness and material properties on the ductility of the braces.

The level of energy dissipation of members of the three materials at the same amplitude of loading were shown to be similar, although higher total energy dissipation to failure of stainless steel members was found owing to the higher number of cycles to failure. For carbon steel members, the energy was relatively higher in hot-rolled than cold-formed specimens. The most significant and crucial difference between the materials were the tangent tensile stiffness of the members. Stainless steel specimens and FE models exhibited higher stiffness than those of the two other materials. These conclusions can have implications on the overall structural response of framed structures.

\section{Acknowledgements}

The financial support of the Outokumpu UK Research Foundation and Corus Tubes UK, as well as the contribution of the laboratory technicians, particularly Gordon Herbert, are very gratefully acknowledged.

\section{REFERENCES}

[1] Elghazouli AY. Seismic design procedures for concentrically braced frames. Proceedings of the Institution of Civil Engineers - Structures and Buildings 2003; 156(4):381-394.

[2] Kahn LF, Hanson, RD. Inelastic cycles of axially loaded steel members. Journal of Structural Engineering, ASCE 1976;102(5):947-959.

[3] Popov EP, Zayas VA, Mahin SA. Cyclic inelastic buckling of thin tubular columns. Journal of the Structural Division, ASCE 1979;105(11):2261-2277.

[4] Jain AK, Goel SC, Hanson RD. Hysteretic cycles of axially loaded steel members. Journal of the Structural Division, ASCE 1980;106(8):1777-1795.

[5] Popov EP, Black RG. Steel struts under severe cyclic loadings. Journal of the Structural Division, ASCE 1981;107(9):1857-1881.

[6] Tang X, Goel SC. Brace fractures and analysis of phase I structure. Journal of Structural Engineering, ASCE 1989;115(8):1960-1976.

[7] Tremblay R. Inelastic seismic response of steel bracing members. Journal of Constructional Steel Research 2002;58(5-8):665-701.

[8] Shaback B, Brown T. Behaviour of square hollow structural steel braces with end connections under reversed cyclic axial loading. Canadian Journal of Civil Engineering 2003;30(4):745-53. 
[9] Goggins JM, Broderick BM, Elghazouli AY, Lucas AS. Behaviour of tubular steel members under cyclic axial loading. Journal of Constructional Steel Research 2006;62(1-2):121-131.

[10] Nip KH, Gardner L, Davies CM, Elghazouli, AY. Extremely low cycle fatigue tests on structural carbon steel and stainless steel. Journal of Constructional Steel Research [submitted for publication].

[11] Nip KH, Gardner L, Elghazouli, AY. Cyclic behaviour of tubular steel braces. Proceedings of the Institution of Civil Engineers - Structures and Buildings [submitted for publication].

[12] EN 1998-1. Design provisions for earthquake resistance of structures - Part 1: General rules, seismic actions and rules for buildings. European Standard, CEN; 2004.

[13] EN 10210-1. Hot finished structural hollow sections of non-alloy and fine grain steels - Part 1: Technical delivery conditions. European Standard, CEN; 2006.

[14] EN 10219-1. Cold formed welded structural hollow sections of non-alloy and fine grain steels - Part 1: Technical delivery conditions. European Standard, CEN; 2006.

[15] EN 10088-2. Stainless steels Part 2: Technical delivery conditions for sheet/plate and strip of corrosion resisting steels for general purposes. European Standard, CEN; 2005.

[16] EN 10002-1. Metallic materials - Tensile testing - Part 1: Method of test at ambient temperature. European Standard, CEN; 2001.

[17] Gardner L, Saari N, Wang F. Comparative experimental study of hot-rolled and cold-formed structural steel hollow sections. Engineering Structures [submitted for publication].

[18] EN 1993-1-1. Design of steel structures - Part 1-1: General rules and rules for buildings. European Standard, CEN; 2005.

[19] Gardner L, Theofanous M. Discrete and continuous treatment of local buckling in stainless steel elements. Journal of Constructional Steel Research 2008;64(11):1207-1216.

[20] EN 1993-1-4. Design of steel structures - Part 1-4: General rules Supplementary rules for stainless steel. European Standard, CEN; 2006.

[21] ECCS. Recommended testing procedure for assessing the behaviour of structural steel elements under cyclic loads. Brussels; 1986.

[22] BS 7270. Metallic materials - Constant amplitude strain controlled axial fatigue - Method of test. British Standards Institution; 2006. 
[23] AISC. Seismic provisions for structural steel buildings. American Institute of Steel Construction, Chicago, IL; 2002.

[24] Remennikov AM, Walpole WR. A note on compression strength reduction factor for a buckled strut in seismic-resisting braced system. Engineering Structures 1998;20(8):779-82.

[25] ABAQUS. Analysis User's Manual I-V. Version 6.7. USA: ABAQUS, Inc., Dassault Systèmes; 2007.

[26] Ellobody E, Young B. Structural performance of cold-formed high strength stainless steel columns. Journal of Constructional Steel Research 2005;61(12):16311649.

[27] Chan TM, Gardner L. Flexural buckling of elliptical hollow section columns. Journal of Structural Engineering, ASCE; 2009;135(5):546-557.

[28] Karren KW. Corner properties of cold-formed steel shapes. Journal of the Structural Division, ASCE 1967;93(ST1):401-432.

[29] Gardner L, Nethercot DA. Numerical modeling of stainless steel structural components - a consistent approach. Journal of Structural Engineering, ASCE 2004;130(10):1586-1601.

[30] Cruise RB, Gardner L. Strength enhancements induced during cold forming of stainless steel sections. Journal of Constructional Steel Research 2008;64(11);13101316.

[31] Dawson RG, Walker AC. Post-buckling of geometrically imperfect plates. Journal of Structural Engineering, ASCE 1972;98(1):75-94.

[32] Walpole WR. Behaviour of cold-formed steel RHS members under cyclic loading. Research Report 96-4, Department of Civil Engineering, University of Canterbury, Christchurch, New Zealand; 1996.

[33] Archambault MH, Tremblay R, Filiatrault A. Etude du comportement seismique des contreventements ductiles en $\mathrm{X}$ avec profiles tubulaires en acier. Rapport no. EPM/GCS-1995-09. Departement de genie civil, Ecole Polytechnique; 1995.

[34] Tremblay R, Archambault MH, Filiatrault A. Seismic response of concentrically braced steel frames made with rectangular hollow bracing members. Journal of Structural Engineering, ASCE. 2003;129(12):1626-1636. 
Table 1. Monotonic tensile material properties

\begin{tabular}{l|c|ccc}
\hline Specimen & $\begin{array}{c}\text { Young's } \\
\text { modulus, E } \\
\left(\mathrm{N} / \mathrm{mm}^{2}\right)\end{array}$ & $\begin{array}{c}\text { Yield strength / } \\
0.2 \% \text { proof } \\
\text { stress, } \mathrm{f}_{\mathrm{y}} \\
\left(\mathrm{N} / \mathrm{mm}^{2}\right)\end{array}$ & $\begin{array}{c}\text { Ultimate } \\
\text { tensile } \\
\text { strength, } \mathrm{f}_{\mathrm{u}} \\
\left(\mathrm{N} / \mathrm{mm}^{2}\right)\end{array}$ & $\begin{array}{c}\text { Percentage } \\
\text { elongation at } \\
\text { fracture, } \\
\varepsilon_{\mathrm{L}}(\%)\end{array}$ \\
\hline $60 \times 60 \times 3-\mathrm{CS}-\mathrm{HR}$ & 215150 & 458 & 555 & 37 \\
$40 \times 40 \times 3-\mathrm{CS}-\mathrm{HR}$ & 219610 & 478 & 555 & 31 \\
\hline $60 \times 60 \times 3-\mathrm{CS}-\mathrm{CF}$ & 207430 & 361 & 402 & 49 \\
$40 \times 40 \times 4-\mathrm{CS}-\mathrm{CF}$ & 201640 & 410 & 430 & 38 \\
$40 \times 40 \times 3-\mathrm{CS}-\mathrm{CF}$ & 212910 & 451 & 502 & 24 \\
\hline $60 \times 60 \times 3-\mathrm{SS}-\mathrm{CF}$ & 197730 & 483 & 745 & 58 \\
$50 \times 50 \times 3-\mathrm{SS}-\mathrm{CF}$ & 197960 & 552 & 798 & 59 \\
$60 \times 40 \times 3-\mathrm{SS}-\mathrm{CF}$ & 191690 & 538 & 753 & 58 \\
\hline
\end{tabular}


Table 2. Measured geometry of test specimens

\begin{tabular}{c|cccc}
\hline $\begin{array}{c}\text { Specimen } \\
\text { identification }\end{array}$ & $\begin{array}{c}\text { Depth } \\
(\mathrm{mm})\end{array}$ & $\begin{array}{c}\text { Width } \\
(\mathrm{mm})\end{array}$ & $\begin{array}{c}\text { Thickness } \\
(\mathrm{mm})\end{array}$ & $\begin{array}{c}\text { Internal } \\
\text { corner radius } \\
(\mathrm{mm})\end{array}$ \\
\hline $60 \times 60 \times 3 \times 2050-\mathrm{CS}-\mathrm{HR}$ & 60.42 & 60.26 & 3.25 & 2.75 \\
$40 \times 40 \times 3 \times 2050-\mathrm{CS}-\mathrm{HR}$ & 40.12 & 39.92 & 2.98 & 1.75 \\
$40 \times 40 \times 3 \times 1250-\mathrm{CS}-\mathrm{HR}$ & 40.12 & 39.92 & 2.98 & 1.75 \\
\hline $60 \times 60 \times 3 \times 2050-\mathrm{CS}-\mathrm{CF}$ & 59.87 & 59.75 & 2.76 & 4.00 \\
$40 \times 40 \times 4 \times 2050-\mathrm{CS}-\mathrm{CF}$ & 40.42 & 40.32 & 3.75 & 3.50 \\
$40 \times 40 \times 3 \times 2050-\mathrm{CS}-\mathrm{CF}$ & 40.13 & 40.01 & 2.79 & 3.00 \\
$40 \times 40 \times 3 \times 1250-\mathrm{CS}-\mathrm{CF}$ & 40.13 & 40.01 & 2.79 & 3.00 \\
\hline $60 \times 60 \times 3 \times 2850-\mathrm{SS}-\mathrm{CF}$ & 60.62 & 60.27 & 2.79 & 2.75 \\
$50 \times 50 \times 3 \times 2850-\mathrm{SS}-\mathrm{CF}$ & 50.19 & 50.03 & 2.76 & 1.00 \\
$60 \times 40 \times 3 \times 2850-\mathrm{SS}-\mathrm{CF}$ & 60.13 & 39.98 & 2.75 & 1.50 \\
$60 \times 60 \times 3 \times 2050-\mathrm{SS}-\mathrm{CF}$ & 60.62 & 60.27 & 2.79 & 2.75 \\
$50 \times 50 \times 3 \times 2050-\mathrm{SS}-\mathrm{CF}$ & 50.19 & 50.07 & 2.76 & 1.00 \\
$60 \times 40 \times 3 \times 2050-\mathrm{SS}-\mathrm{CF}$ & 60.13 & 39.98 & 2.75 & 1.50 \\
$60 \times 60 \times 3 \times 1250-\mathrm{SS}-\mathrm{CF}$ & 60.62 & 60.27 & 2.79 & 2.75 \\
$50 \times 50 \times 3 \times 1250-\mathrm{SS}-\mathrm{CF}$ & 50.19 & 50.03 & 2.76 & 1.00 \\
$60 \times 40 \times 3 \times 1250-\mathrm{SS}-\mathrm{CF}$ & 60.13 & 39.98 & 2.75 & 1.50 \\
\hline
\end{tabular}


Table 3. Summary of test results.

\begin{tabular}{|c|c|c|c|c|c|c|c|c|}
\hline \multirow[b]{2}{*}{ Specimen identification } & \multirow[b]{2}{*}{$\begin{array}{c}\text { Yield } \\
\text { displacement } \\
(\mathrm{mm})\end{array}$} & \multirow[b]{2}{*}{$\mathrm{b} / \mathrm{t} \varepsilon$} & \multirow[b]{2}{*}{$\bar{\lambda}$} & \multicolumn{4}{|c|}{ Number of cycles to } & \multirow[b]{2}{*}{$\begin{array}{l}\text { Displacement } \\
\text { ductility }\end{array}$} \\
\hline & & & & $\begin{array}{c}\text { global } \\
\text { buckling }\end{array}$ & $\begin{array}{c}\text { local } \\
\text { buckling }\end{array}$ & $\begin{array}{c}\text { corner } \\
\text { opening }\end{array}$ & $\begin{array}{c}\text { Final } \\
\text { fracture }\end{array}$ & \\
\hline $60 \times 60 \times 3 \times 2050-\mathrm{CS}-\mathrm{HR}$ & 4.31 & 20.6 & 0.57 & 5 & 7 & 10 & 11 & 4 \\
\hline $40 \times 40 \times 3 \times 2050-$ CS-HR & 4.92 & 14.7 & 0.89 & 4 & 15 & 18 & 20 & 10 \\
\hline $40 \times 40 \times 3 \times 1250-$ CS-HR & 3.00 & 14.7 & 0.50 & 5 & 8 & 11 & 15 & 6 \\
\hline $60 \times 60 \times 3 \times 2050-\mathrm{CS}-\mathrm{CF}$ & 4.51 & 20.8 & 0.53 & 5 & 7 & 10 & 11 & 4 \\
\hline $40 \times 40 \times 4 \times 2050-\mathrm{CS}-\mathrm{CF}^{*}$ & 4.51 & 9.1 & 0.89 & 4 & - & 11 & $14^{*}$ & 6 \\
\hline $40 \times 40 \times 3 \times 2050-\mathrm{CS}-\mathrm{CF}^{*}$ & 5.95 & 14.2 & 0.90 & 3 & 5 & 10 & $11^{*}$ & 4 \\
\hline $40 \times 40 \times 3 \times 1250-\mathrm{CS}-\mathrm{CF}$ & 3.63 & 14.2 & 0.50 & 4 & 8 & 10 & 11 & 4 \\
\hline $60 \times 60 \times 3 \times 2850-\mathrm{SS}-\mathrm{CF}$ & 7.41 & 25.5 & 0.89 & 3 & 8 & 10 & 10 & 4 \\
\hline $50 \times 50 \times 3 \times 2850-\mathrm{SS}-\mathrm{CF}$ & 8.27 & 23.7 & 1.16 & 3 & 12 & 14 & 14 & 8 \\
\hline $60 \times 40 \times 3 \times 2850-$ SS-CF $^{*}$ & 8.55 & 28.4 & 1.40 & 3 & - & 10 & $11^{*}$ & 4 \\
\hline $60 \times 60 \times 3 \times 2050-\mathrm{SS}-\mathrm{CF}$ & 5.33 & 25.5 & 0.62 & 5 & 8 & 9 & 10 & 4 \\
\hline $50 \times 50 \times 3 \times 2050-\mathrm{SS}-\mathrm{CF}$ & 5.95 & 23.7 & 0.80 & 4 & 8 & 10 & 11 & 4 \\
\hline $60 \times 40 \times 3 \times 2050-\mathrm{SS}-\mathrm{CF}$ & 6.15 & 28.4 & 0.97 & 4 & 8 & 11 & 11 & 6 \\
\hline $60 \times 60 \times 3 \times 1250-\mathrm{SS}-\mathrm{CF}$ & 3.25 & 25.5 & 0.34 & 5 & 8 & 10 & 11 & 4 \\
\hline $50 \times 50 \times 3 \times 1250-\mathrm{SS}-\mathrm{CF}$ & 3.63 & 23.7 & 0.45 & 5 & 8 & 10 & 11 & 4 \\
\hline $60 \times 40 \times 3 \times 1250-\mathrm{SS}-\mathrm{CF}$ & 3.75 & 28.4 & 0.54 & 5 & 6 & 10 & 10 & 4 \\
\hline
\end{tabular}

* Specimen failed at end connection. 
Table 4. Verification of FE models

\begin{tabular}{|c|c|c|c|c|}
\hline \multirow{3}{*}{ Specimen identification } & \multicolumn{4}{|c|}{ Number of cycles to } \\
\hline & \multicolumn{2}{|c|}{$\begin{array}{c}\text { local } \\
\text { buckling }\end{array}$} & \multicolumn{2}{|c|}{ fracture } \\
\hline & Test & $\mathrm{FE}$ & Test & $\mathrm{FE}$ \\
\hline $60 \times 60 \times 3 \times 2050-\mathrm{CS}-\mathrm{HR}$ & 7 & 8 & 10 & 9 \\
\hline $40 \times 40 \times 3 \times 2050-$ CS-HR & 15 & 9 & 18 & 12 \\
\hline $40 \times 40 \times 3 \times 1250-\mathrm{CS}-\mathrm{HR}$ & 8 & 8 & 11 & 10 \\
\hline $60 \times 60 \times 3 \times 2050-C S-C F$ & 7 & 5 & 10 & 8 \\
\hline $40 \times 40 \times 4 \times 2050-\mathrm{CS}-\mathrm{CF}$ & - & 11 & 11 & 13 \\
\hline $40 \times 40 \times 3 \times 2050-\mathrm{CS}-\mathrm{CF}$ & 5 & 8 & 10 & 10 \\
\hline $40 \times 40 \times 3 \times 1250-\mathrm{CS}-\mathrm{CF}$ & 8 & 6 & 10 & 8 \\
\hline $60 \times 60 \times 3 \times 2850-\mathrm{SS}-\mathrm{CF}$ & 8 & 8 & 10 & 10 \\
\hline $50 \times 50 \times 3 \times 2850-\mathrm{SS}-\mathrm{CF}$ & 12 & 10 & 14 & 12 \\
\hline $60 \times 40 \times 3 \times 2850-\mathrm{SS}-\mathrm{CF}$ & - & 9 & 10 & 11 \\
\hline $60 \times 60 \times 3 \times 2050-\mathrm{SS}-\mathrm{CF}$ & 8 & 8 & 9 & 9 \\
\hline $50 \times 50 \times 3 \times 2050-\mathrm{SS}-\mathrm{CF}$ & 8 & 8 & 10 & 10 \\
\hline $60 \times 40 \times 3 \times 2050-\mathrm{SS}-\mathrm{CF}$ & 8 & 8 & 11 & 10 \\
\hline $60 \times 60 \times 3 \times 1250-\mathrm{SS}-\mathrm{CF}$ & 8 & 8 & 10 & 10 \\
\hline $50 \times 50 \times 3 \times 1250-\mathrm{SS}-\mathrm{CF}$ & 8 & 8 & 10 & 9 \\
\hline $60 \times 40 \times 3 \times 1250-\mathrm{SS}-\mathrm{CF}$ & 6 & 5 & 10 & 9 \\
\hline $40 \times 40 \times 2.5 \times 1100-$ CS$^{2} \mathrm{CF}^{*}$ & - & 8 & 14 & 9 \\
\hline $50 \times 25 \times 2.5 \times 1100-$ CS$^{-C F}{ }^{*}$ & - & 7 & 17 & 9 \\
\hline $150 \times 100 \times 6 \times 2704-\mathrm{CS}^{-C^{*}} *$ & - & 5 & 7 & 6 \\
\hline
\end{tabular}

* Tests results from Goggins et al. [9] and Walpole [32]; number of cycles at which local buckling occurred was not reported 
Table 5. Comparison between predicted displacement ductility by various equations and displacement ductility obtained from FE models or experiments

\begin{tabular}{|c|c|c|c|c|c|c|c|}
\hline \multirow{3}{*}{ References } & \multirow{3}{*}{ Equation } & \multicolumn{6}{|c|}{ Prediction / FE or Prediction / test } \\
\hline & & \multicolumn{2}{|c|}{ Hot CS } & \multicolumn{2}{|c|}{ Cold CS } & \multicolumn{2}{|c|}{ Cold SS } \\
\hline & & Mean & C.O.V. & Mean & C.O.V. & Mean & C.O.V. \\
\hline $\begin{array}{l}\text { Tremblay } \\
{[7]}\end{array}$ & $\mu_{\Delta}=2.3+8.3 \bar{\lambda}$ & 1.80 & 0.34 & 1.95 & 0.45 & $(1.55)$ & $(0.33)$ \\
\hline \multirow{2}{*}{$\begin{array}{l}\text { Goggins et } \\
\text { al. [9] }\end{array}$} & $\mu_{\Delta}=-0.7+26.2 \bar{\lambda}$ & $(3.08)$ & $(0.53)$ & 3.15 & 0.65 & $(2.42)$ & $(0.47)$ \\
\hline & $\mu_{\Delta}=29.1-1.07(\mathrm{~b} / \mathrm{t})$ & $(2.55)$ & $(0.31)$ & 2.76 & 0.36 & $(2.08)$ & $(0.35)$ \\
\hline \multirow{3}{*}{$\begin{array}{l}\text { Current } \\
\text { study }\end{array}$} & $\begin{array}{l}\mu_{\Delta}=3.69+6.97 \bar{\lambda} \\
-0.05(\mathrm{~b} / \mathrm{t} \varepsilon)-0.19(\bar{\lambda})(\mathrm{b} / \mathrm{t} \varepsilon)\end{array}$ & 1.03 & 0.18 & - & - & - & - \\
\hline & $\begin{array}{l}\mu_{\Delta}=6.45+2.28 \bar{\lambda} \\
-0.11(\mathrm{~b} / \mathrm{t} \varepsilon)-0.06(\bar{\lambda})(\mathrm{b} / \mathrm{t} \varepsilon)\end{array}$ & - & - & 1.10 & 0.30 & - & - \\
\hline & $\begin{array}{l}\mu_{\Delta}=-3.42+19.86 \bar{\lambda} \\
+0.21(\mathrm{~b} / \mathrm{t} \varepsilon)-0.64(\bar{\lambda})(\mathrm{b} / \mathrm{t} \varepsilon)\end{array}$ & - & - & - & - & 1.02 & 0.21 \\
\hline
\end{tabular}

* Values in brackets indicate that the equation has not been derived from a database consisting of specimens of that material. 


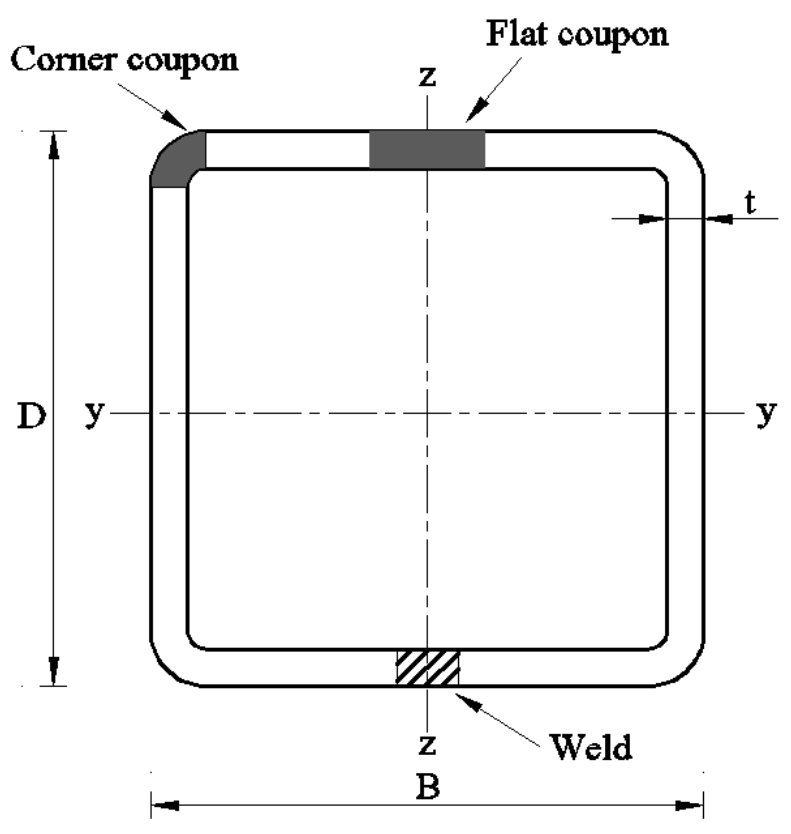

Fig. 1: Section labelling convention and location of flat and corner tensile coupons

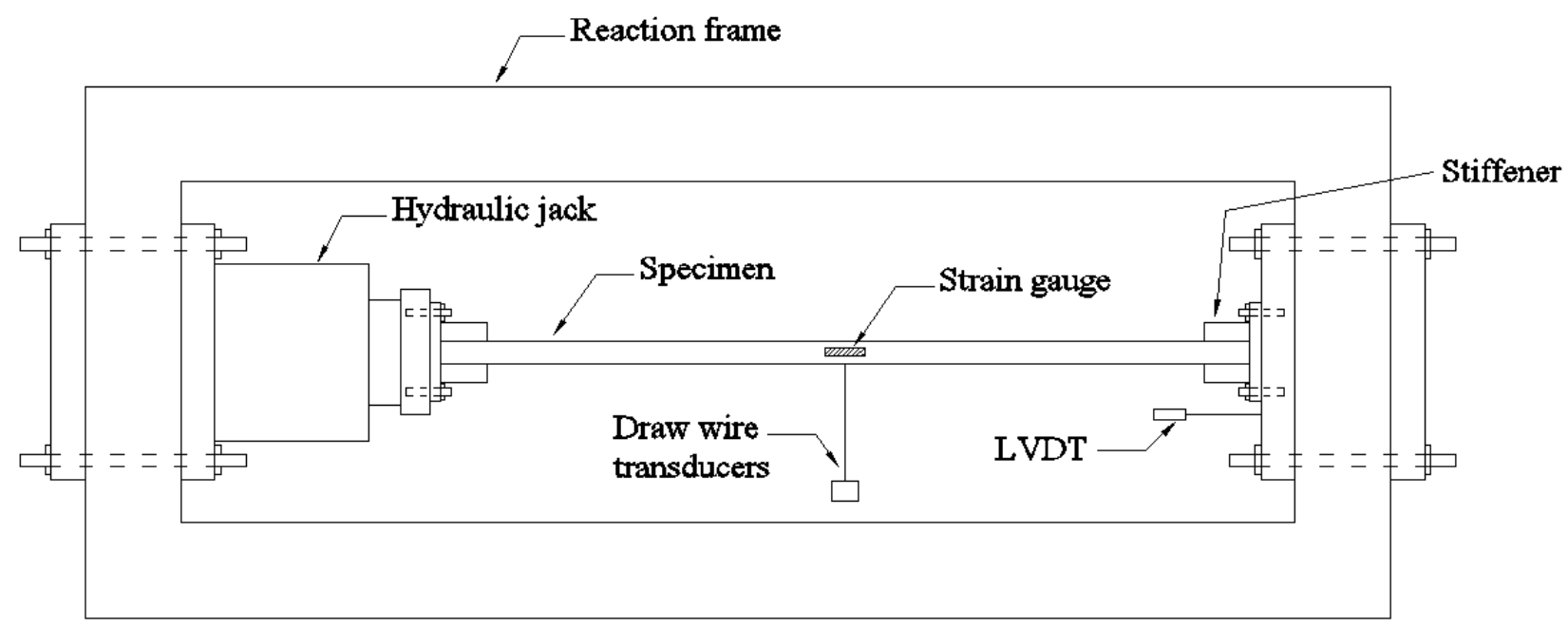

Fig. 2: Schematic diagram of the test set-up (plan view) 


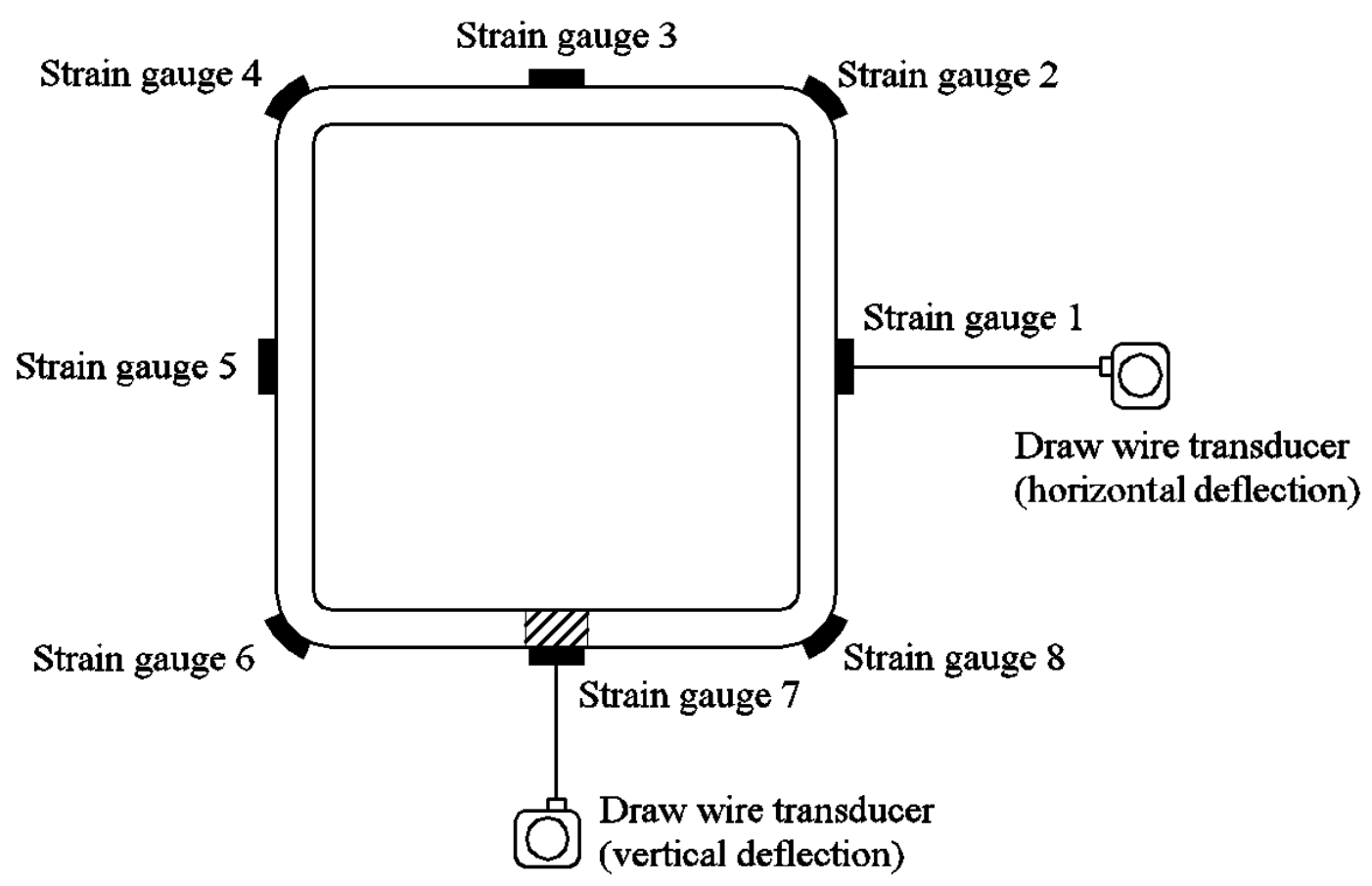

Fig. 3: Instrumentation on the cross-section at mid-length of the members

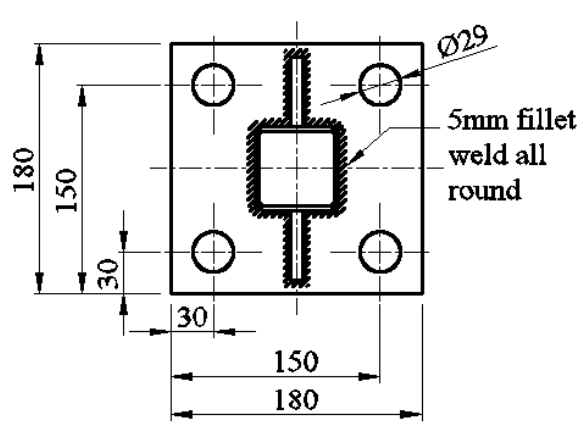

Plan

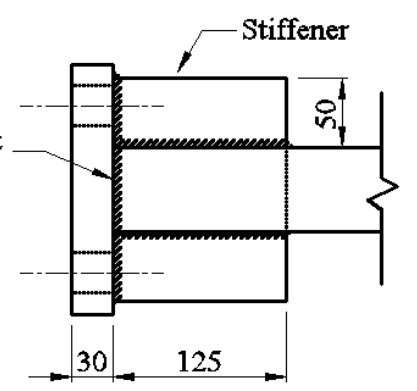

Elevation

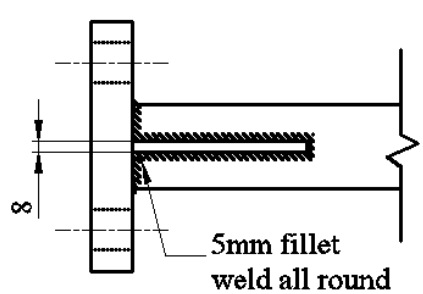

Side view

Fig. 4: End connection details of test specimens (dimensions in $\mathrm{mm}$ ) 


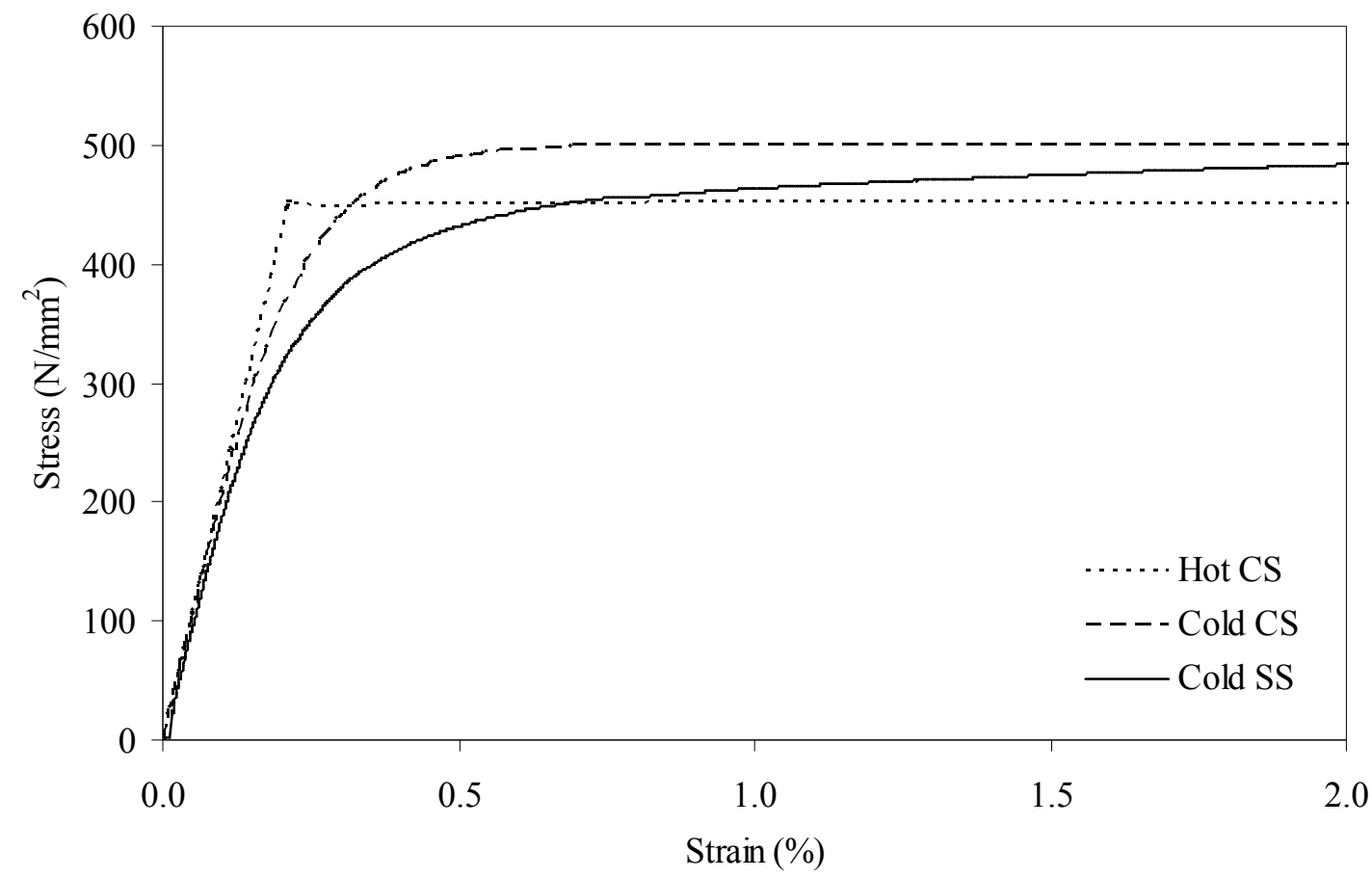

Fig. 5: Typical monotonic tensile stress-strain curves of flat materials from hot-rolled carbon steel, cold-formed carbon steel and cold-formed stainless steel specimens.

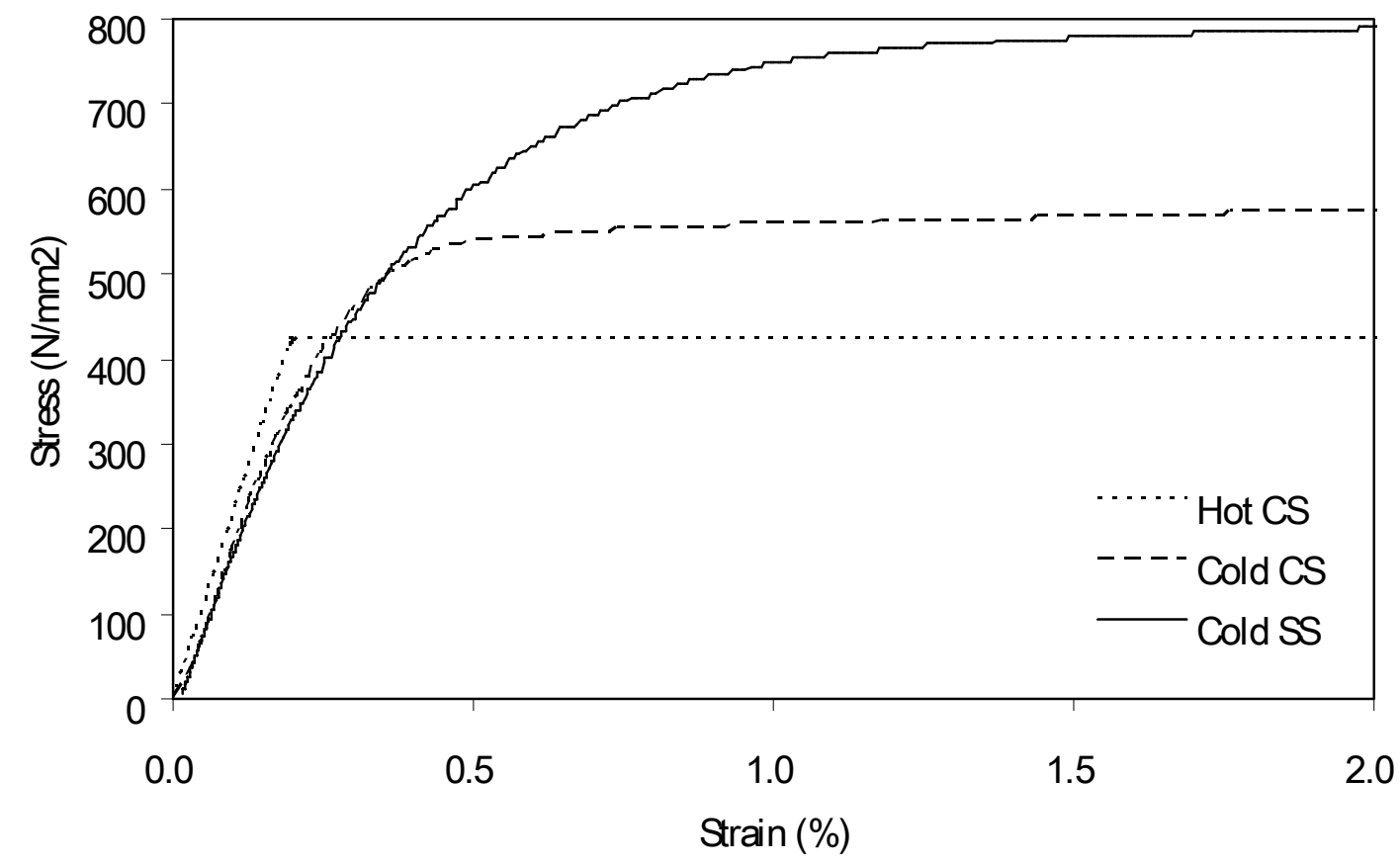

Fig. 6: Typical monotonic tensile stress-strain curves of corner materials from hotrolled carbon steel, cold-formed carbon steel and cold-formed stainless steel specimens. 


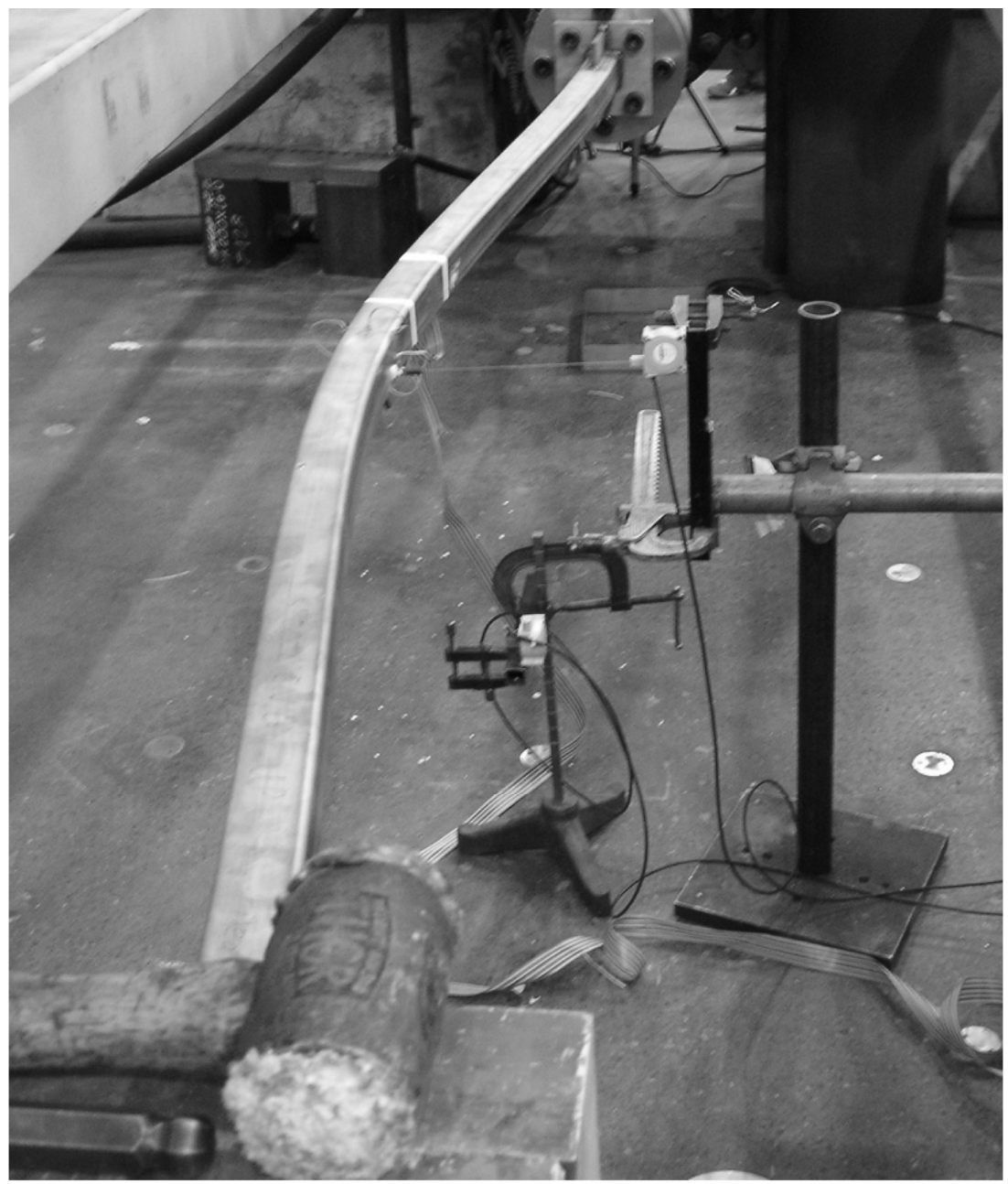

Fig. 7: Buckling of Specimen $60 \times 60 \times 3 \times 2850-\mathrm{SS}-\mathrm{CF}$ 


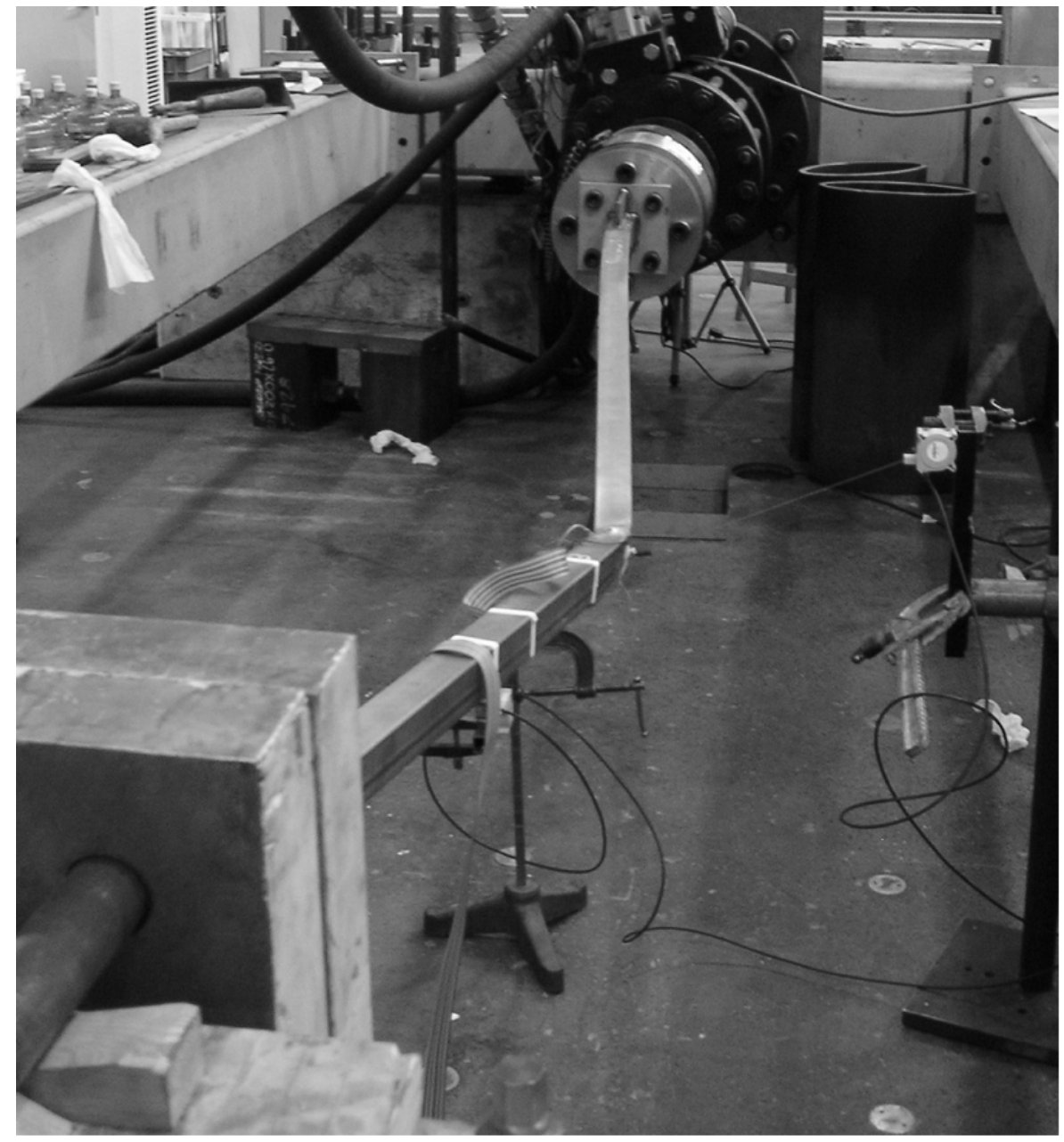

Fig. 8: Formation of a plastic mechanism in Specimen $50 \times 50 \times 3 \times 2850-\mathrm{SS}-\mathrm{CF}$ 


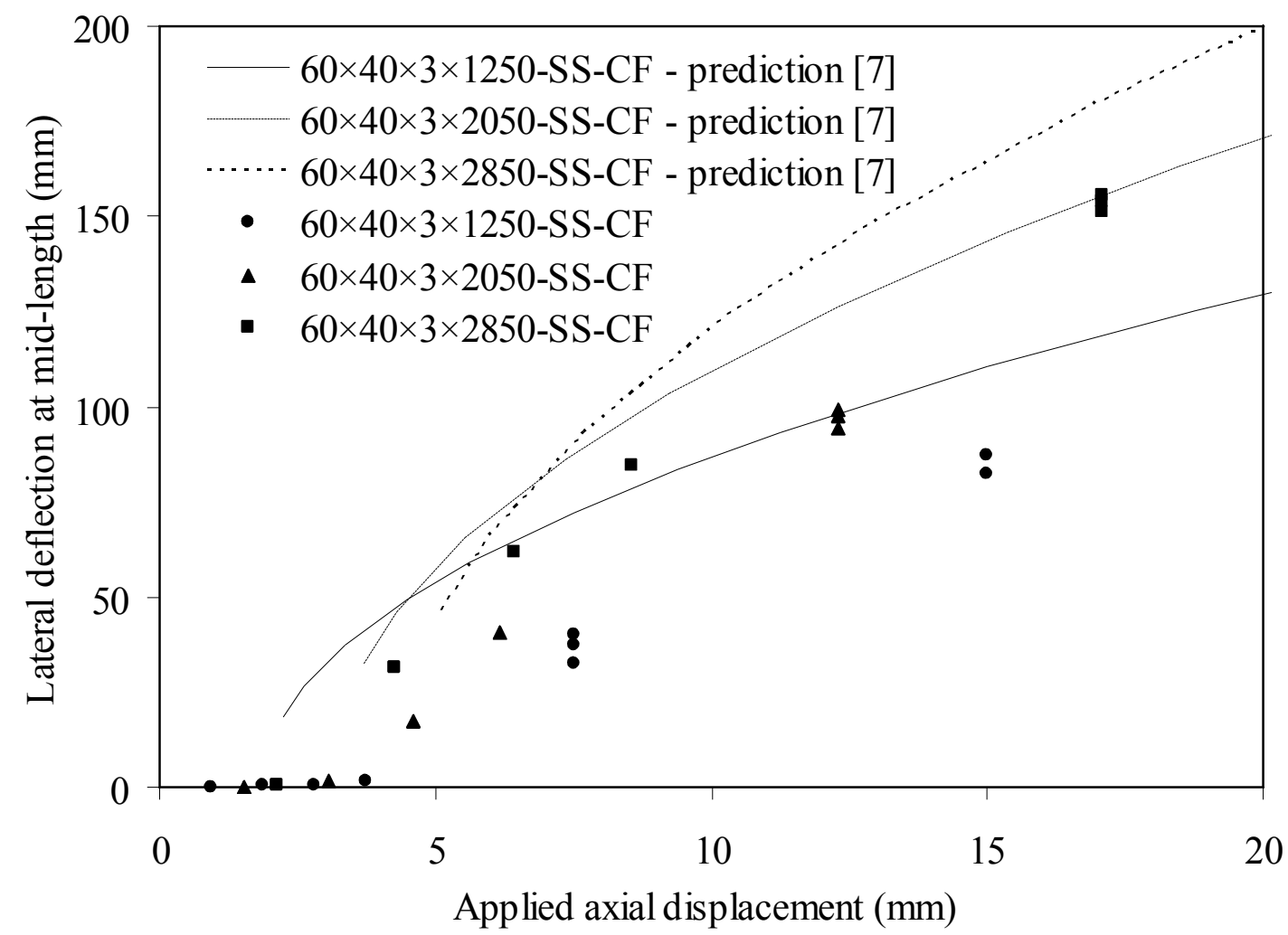

Fig. 9: Deflection at mid-length for three specimens with different global slenderness

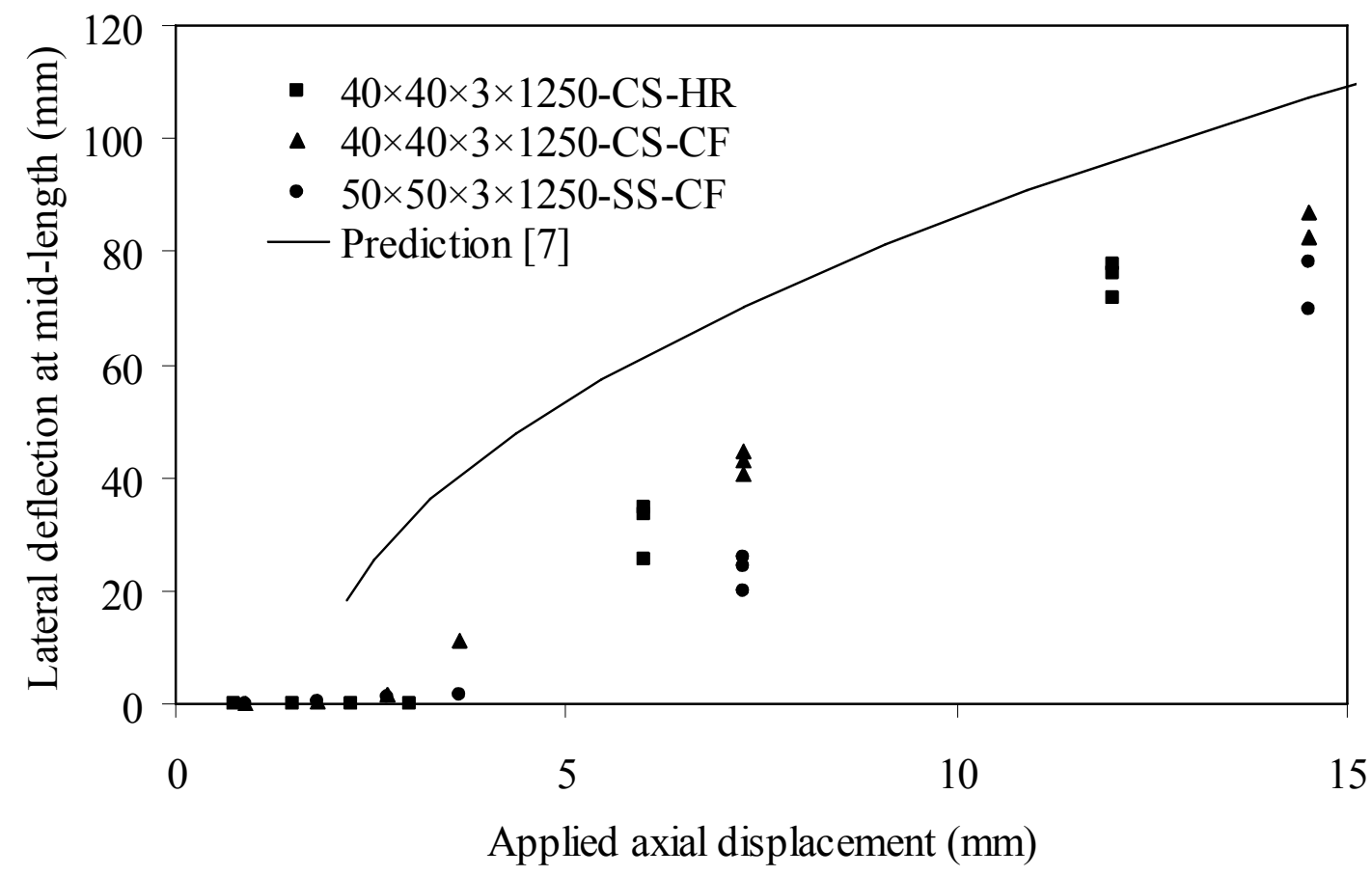

Fig. 10: Deflection at mid-length for three specimens with similar global slenderness 

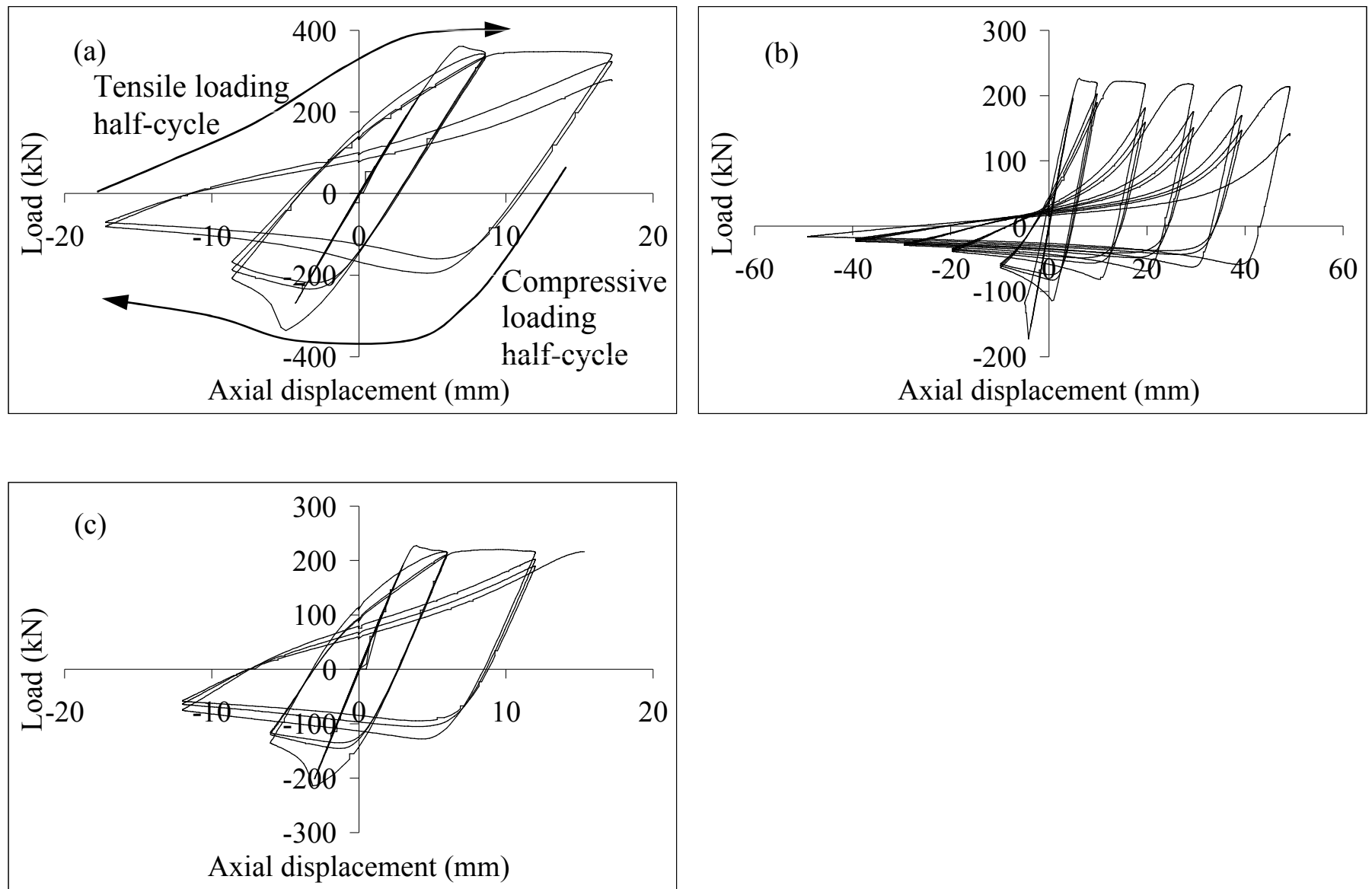

Figs 11(a)-(c): Load-displacement hysteretic loops for (a) Specimen $60 \times 60 \times 3 \times 2050$ CS-HR, (b) $40 \times 40 \times 3 \times 2050-C S-H R$ and (c) $40 \times 40 \times 3 \times 1250-C S-H R$ 

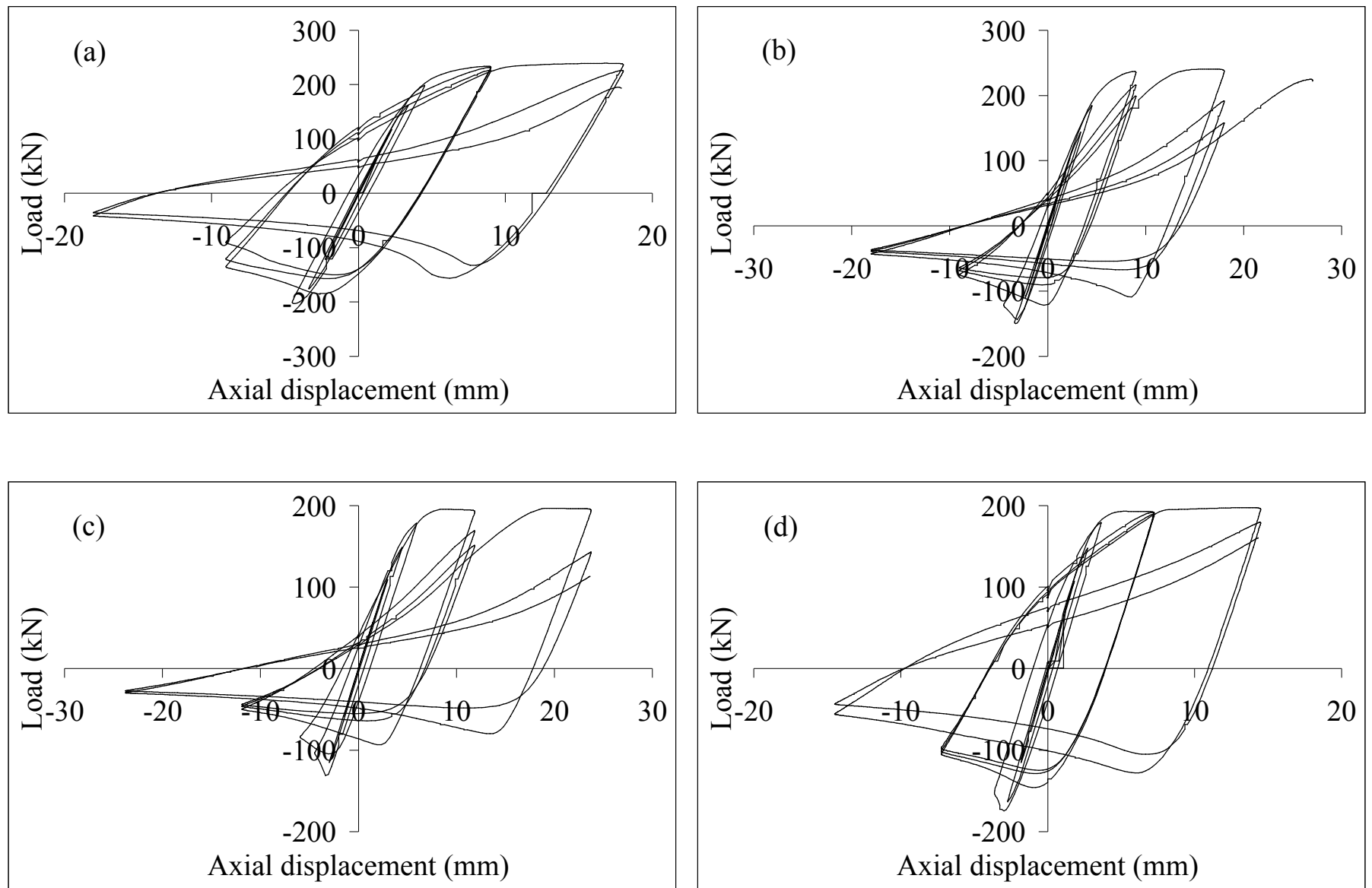

Figs 12(a)-(d): Load-displacement hysteretic loops for Specimens (a) $60 \times 60 \times 3 \times 2050-\mathrm{CS}-\mathrm{CF}$, (b) $40 \times 40 \times 4 \times 2050-\mathrm{CS}-\mathrm{CF}$, (c) $40 \times 40 \times 3 \times 2050-\mathrm{CS}-\mathrm{CF}$ and (d) $40 \times 40 \times 3 \times 1250-\mathrm{CS}-\mathrm{CF}$ 

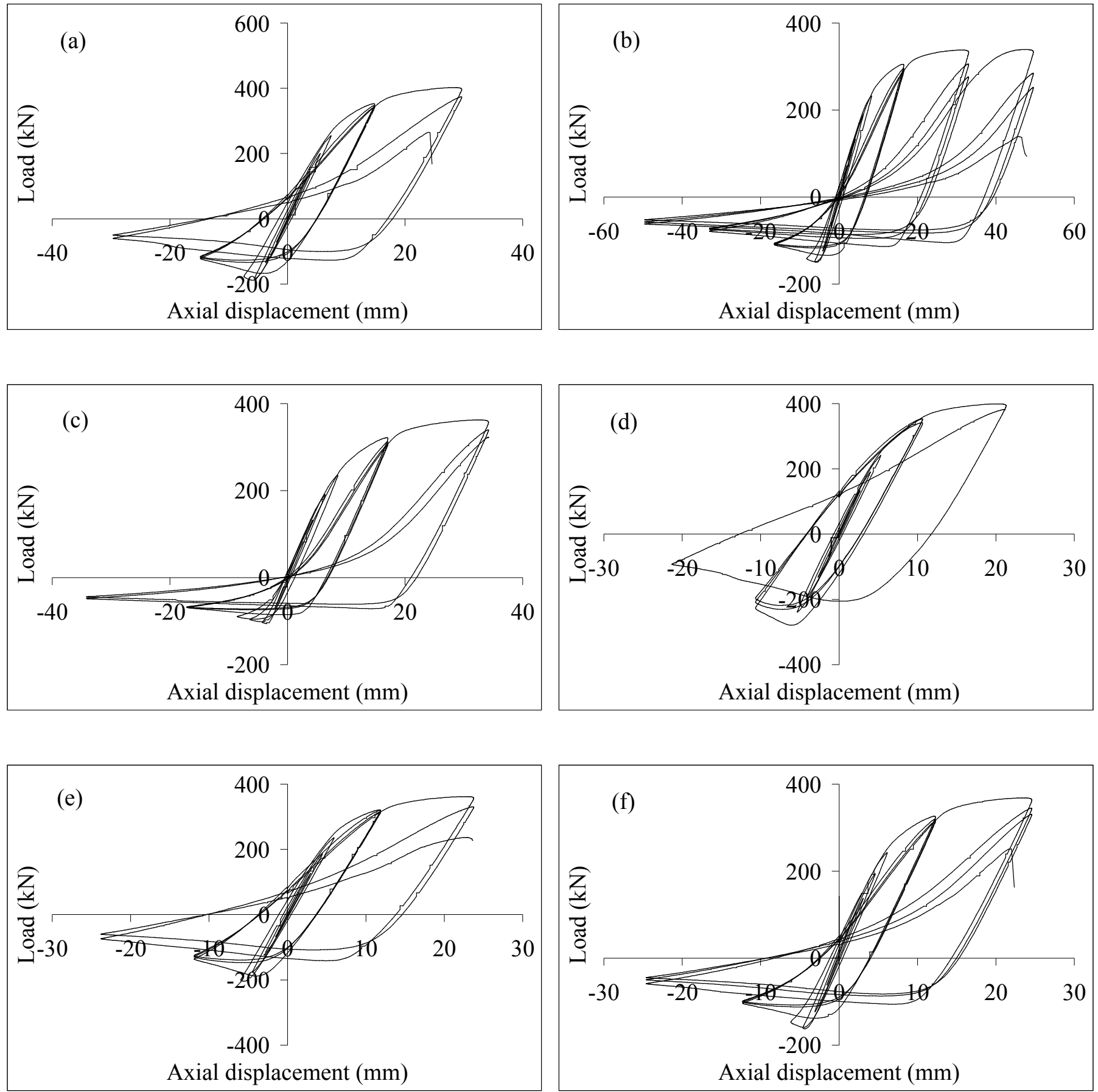

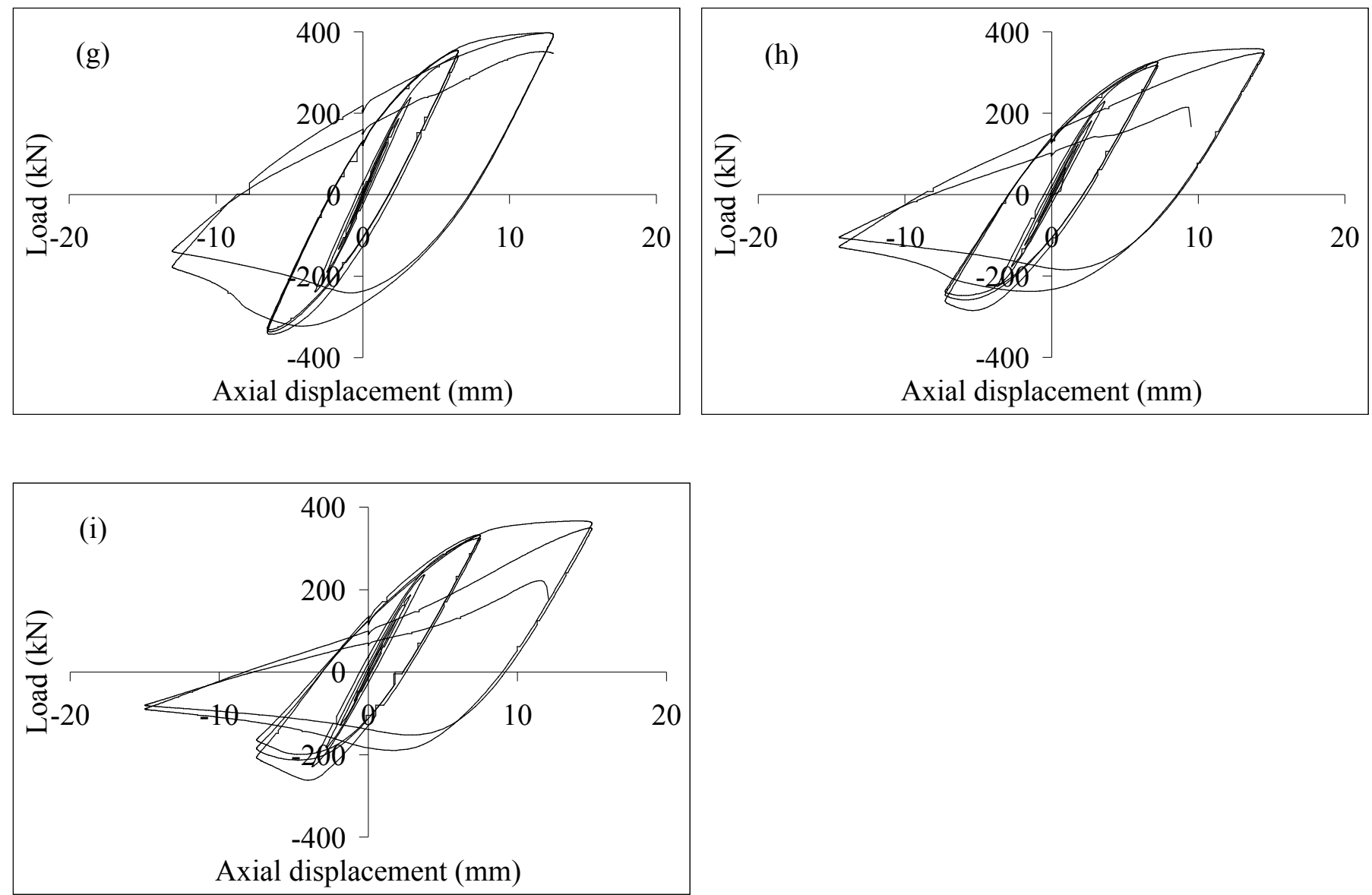

Figs 13(a)-(i): Load-displacement hysteretic loops for Specimens (a) $60 \times 60 \times 3 \times 2850$ SS-CF, (b) $50 \times 50 \times 3 \times 2850-S S-C F$, (c) $60 \times 40 \times 3 \times 2850-S S-C F$, (d) $60 \times 60 \times 3 \times 2050-$ SS-CF, (e) $50 \times 50 \times 3 \times 2050$-SS-CF, (f) $60 \times 40 \times 3 \times 2050$-SS-CF, (g) $60 \times 60 \times 3 \times 1250$-SS$\mathrm{CF}$, (h) $50 \times 50 \times 3 \times 1250-\mathrm{SS}-\mathrm{CF}$, and (i) $60 \times 40 \times 3 \times 1250-\mathrm{SS}-\mathrm{CF}$ 


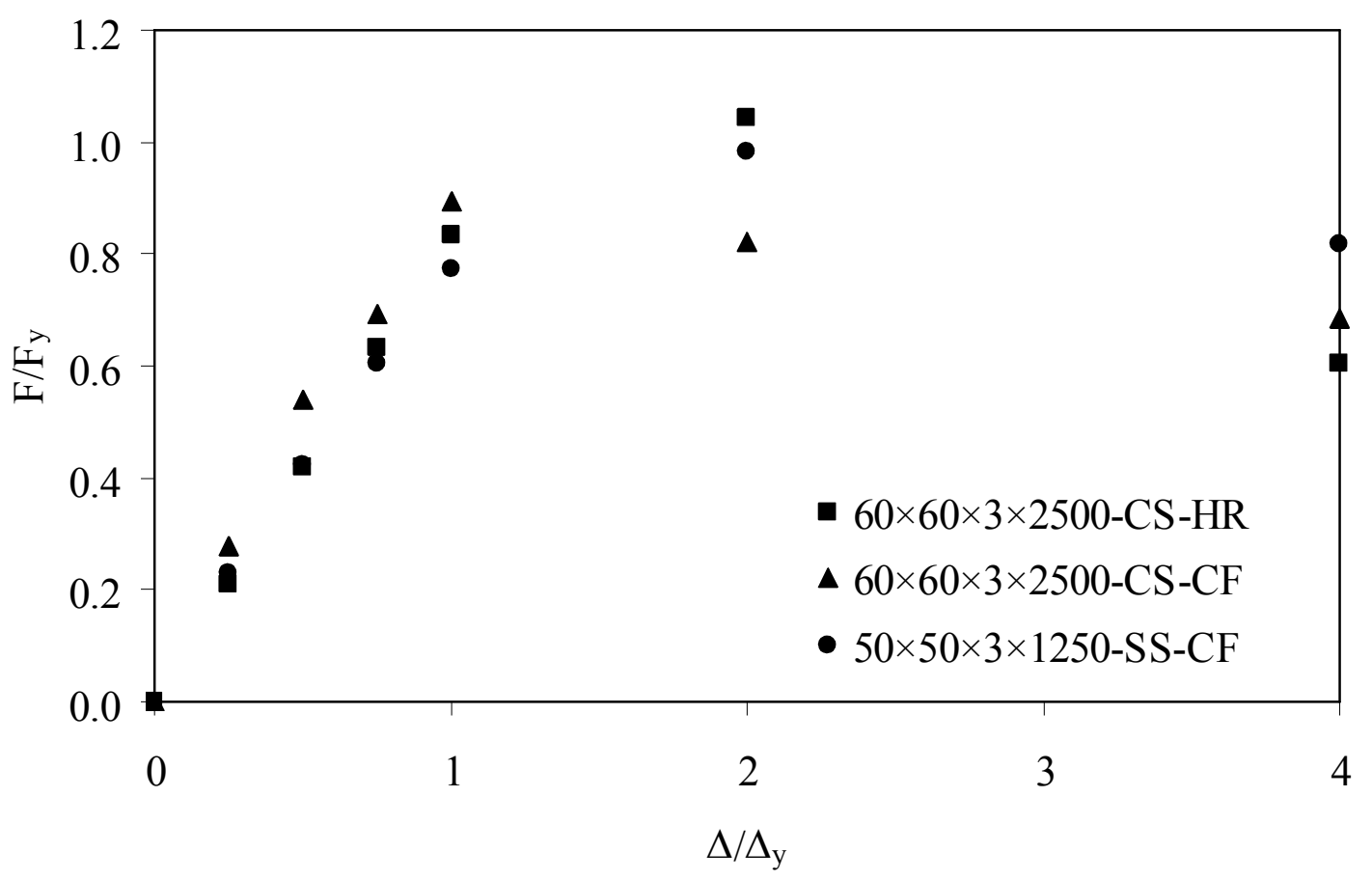

Fig. 14: Maximum compressive resistance at various displacement amplitudes

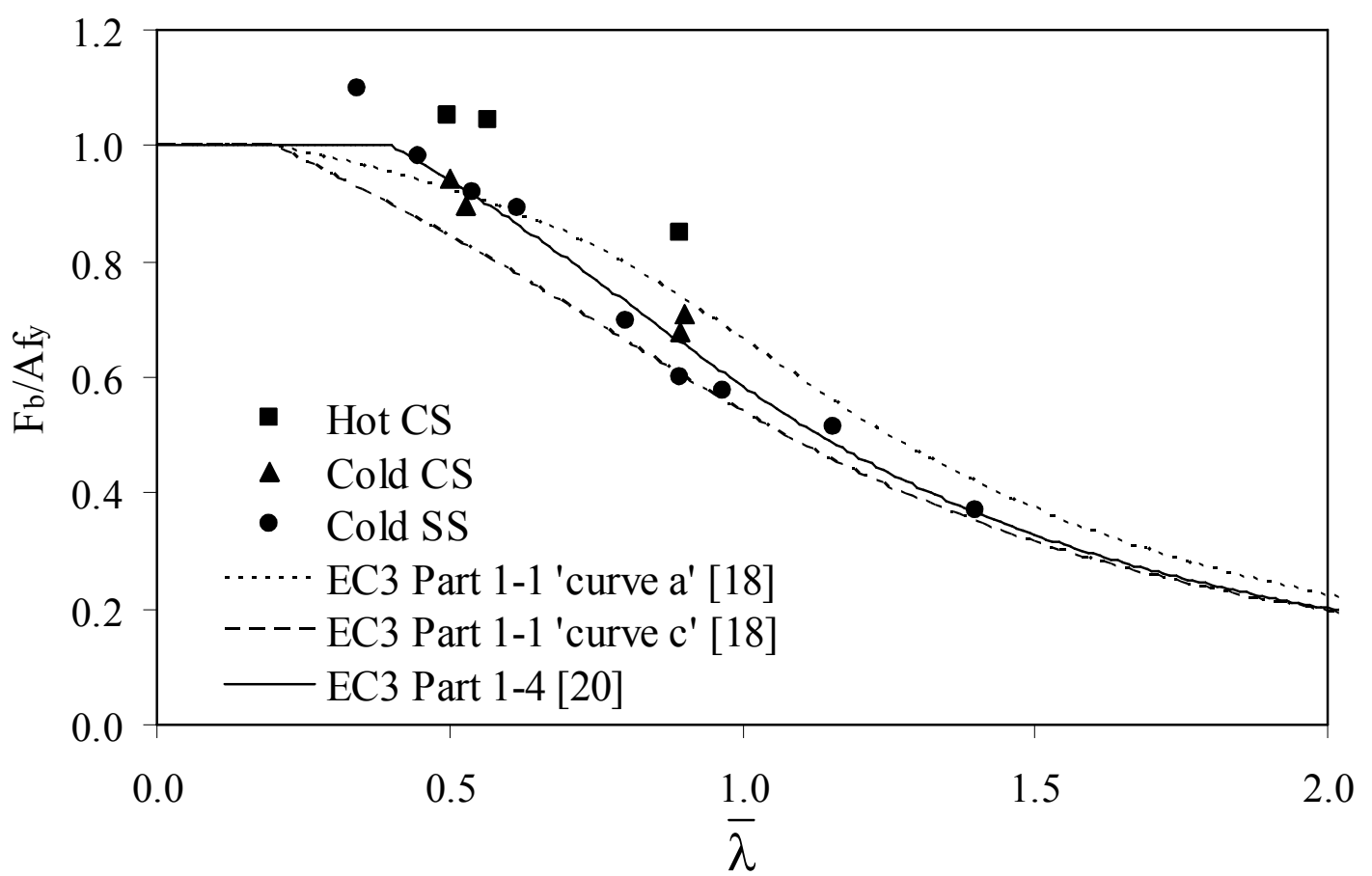

Fig. 15: Normalised initial buckling load of cyclic specimens compared with static buckling load given by Eurocode 3 . 


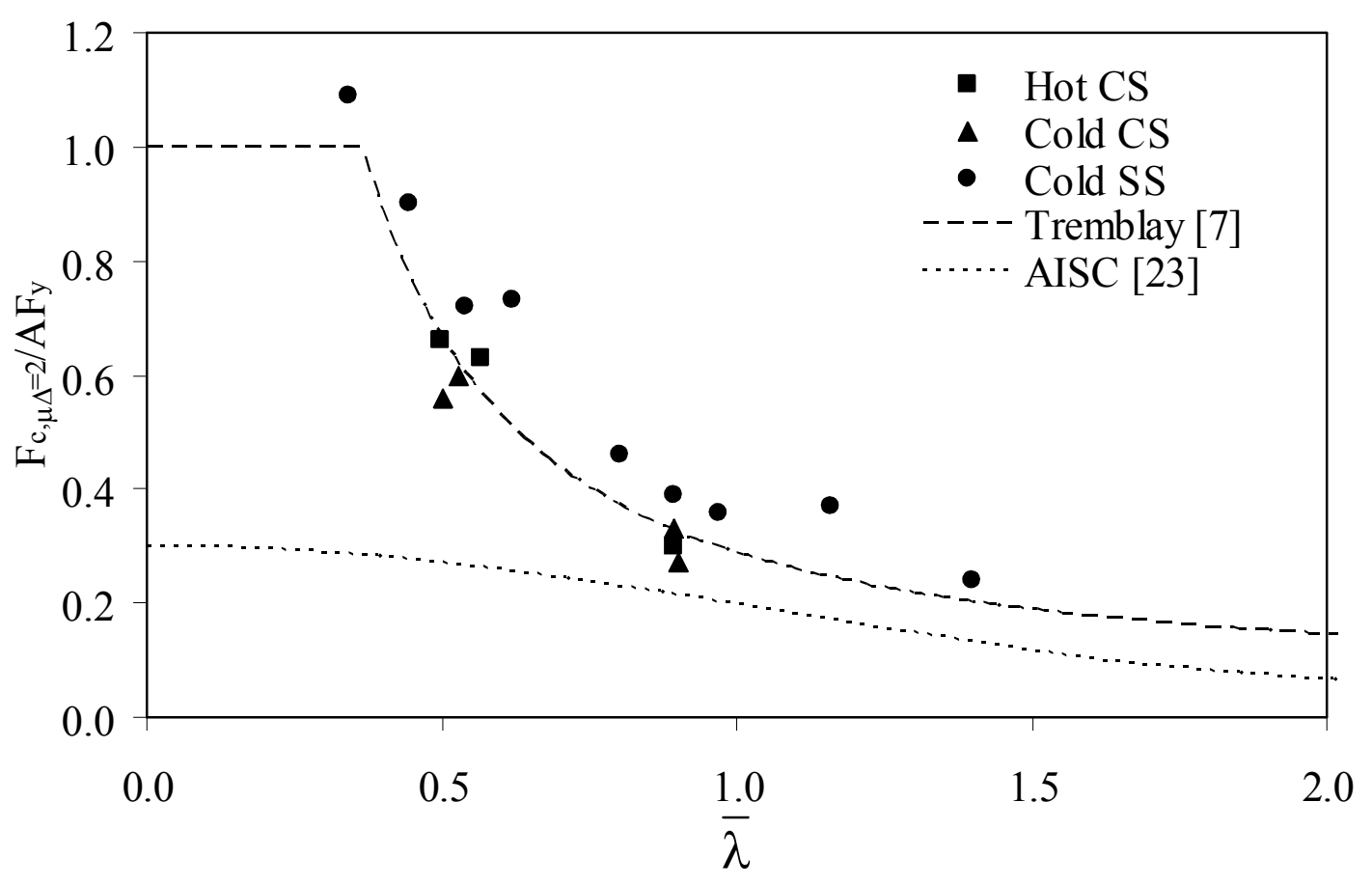

Fig. 16: Normalised compressive resistance at compression displacement of $2 \Delta_{\mathrm{y}}$ for cyclic specimens compared with prediction by Tremblay [7] and AISC [23].

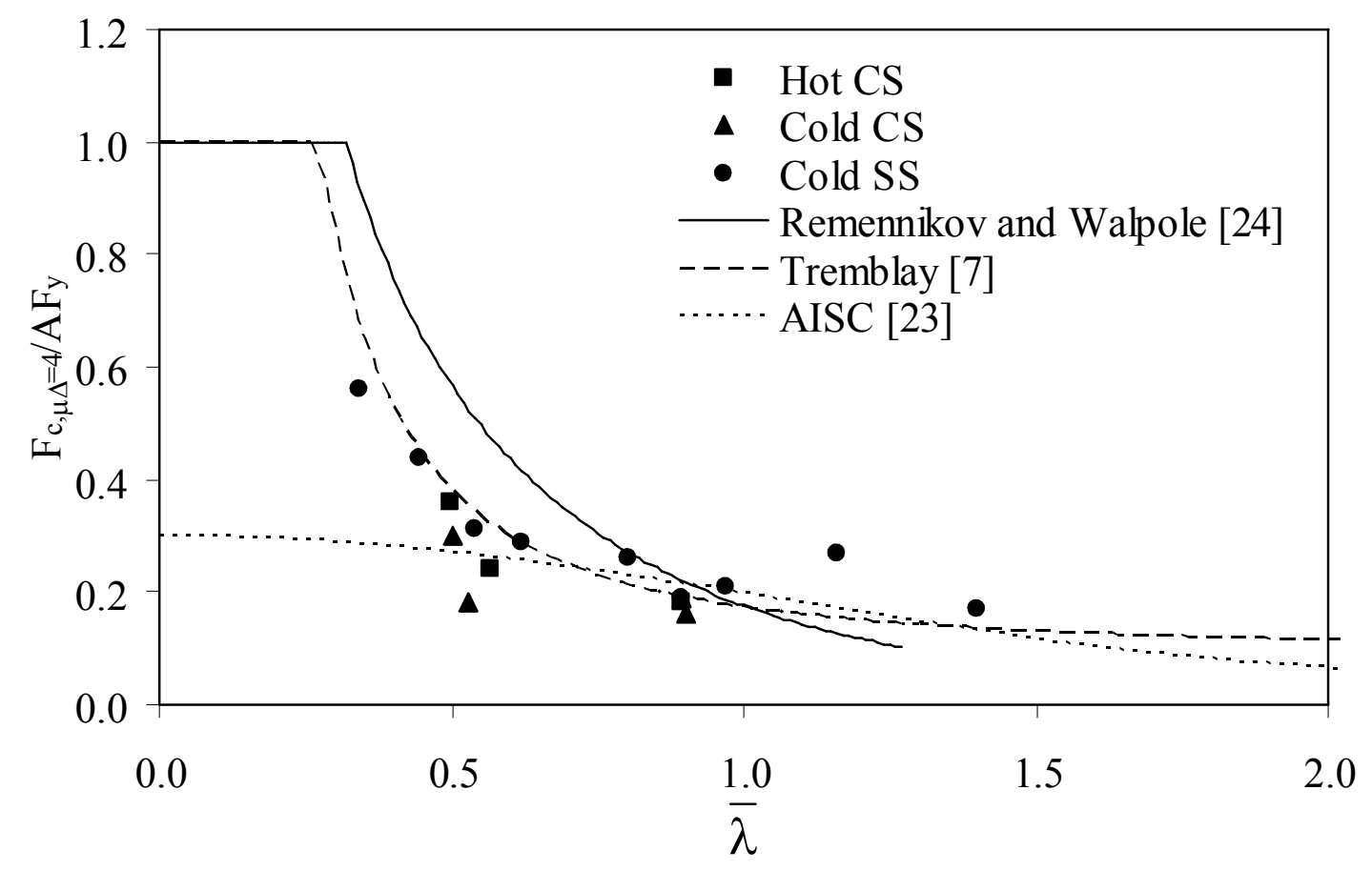

Fig. 17: Normalised compressive resistance at compression displacement of $4 \Delta_{\mathrm{y}}$ for cyclic specimens compared with prediction by Remennikov and Walpole [24], Tremblay [7] and AISC [23]. 


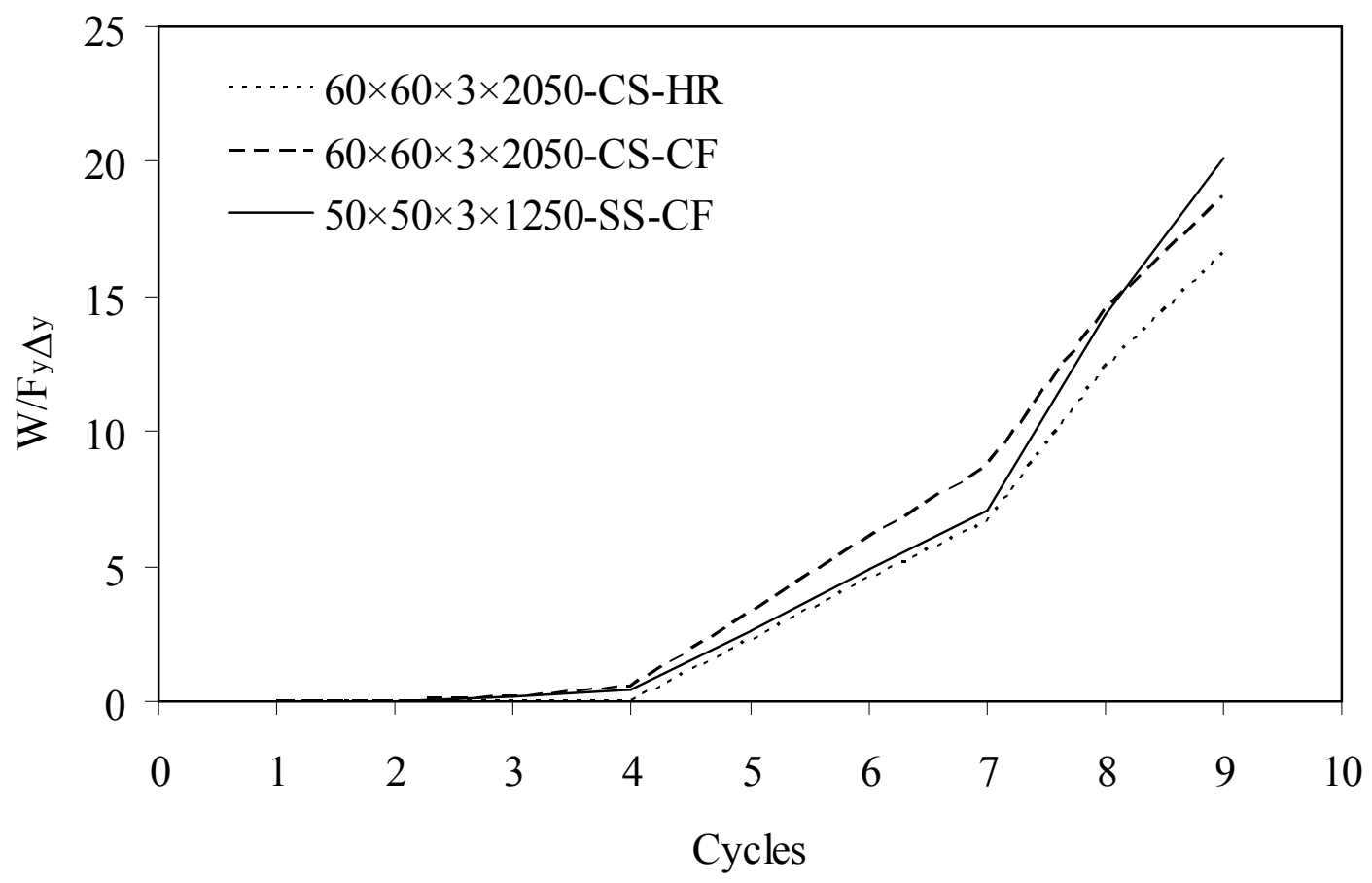

Fig. 18: Accumulated normalised energy dissipation

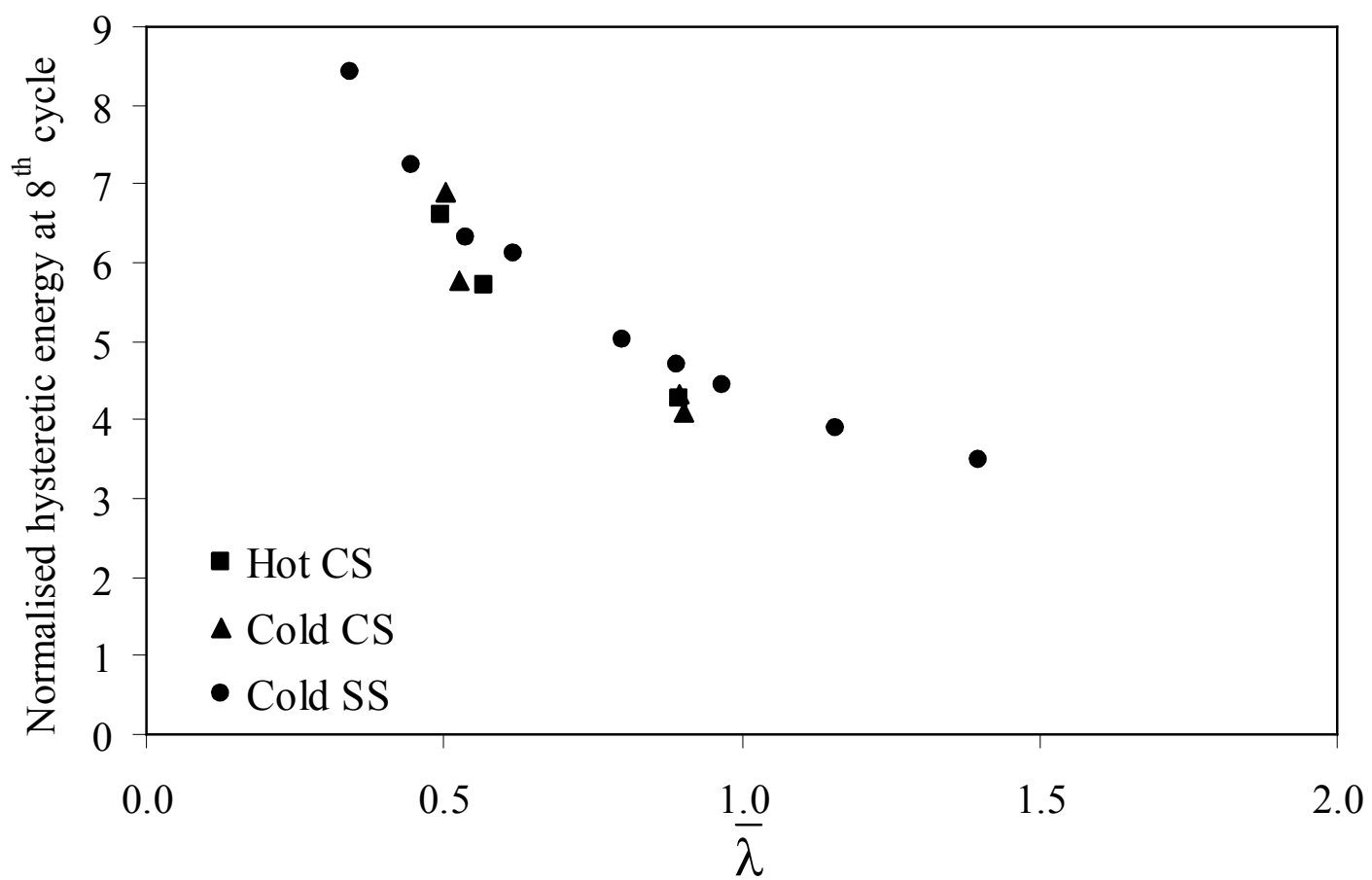

Fig. 19: Normalised energy dissipation at the $8^{\text {th }}$ cycle 

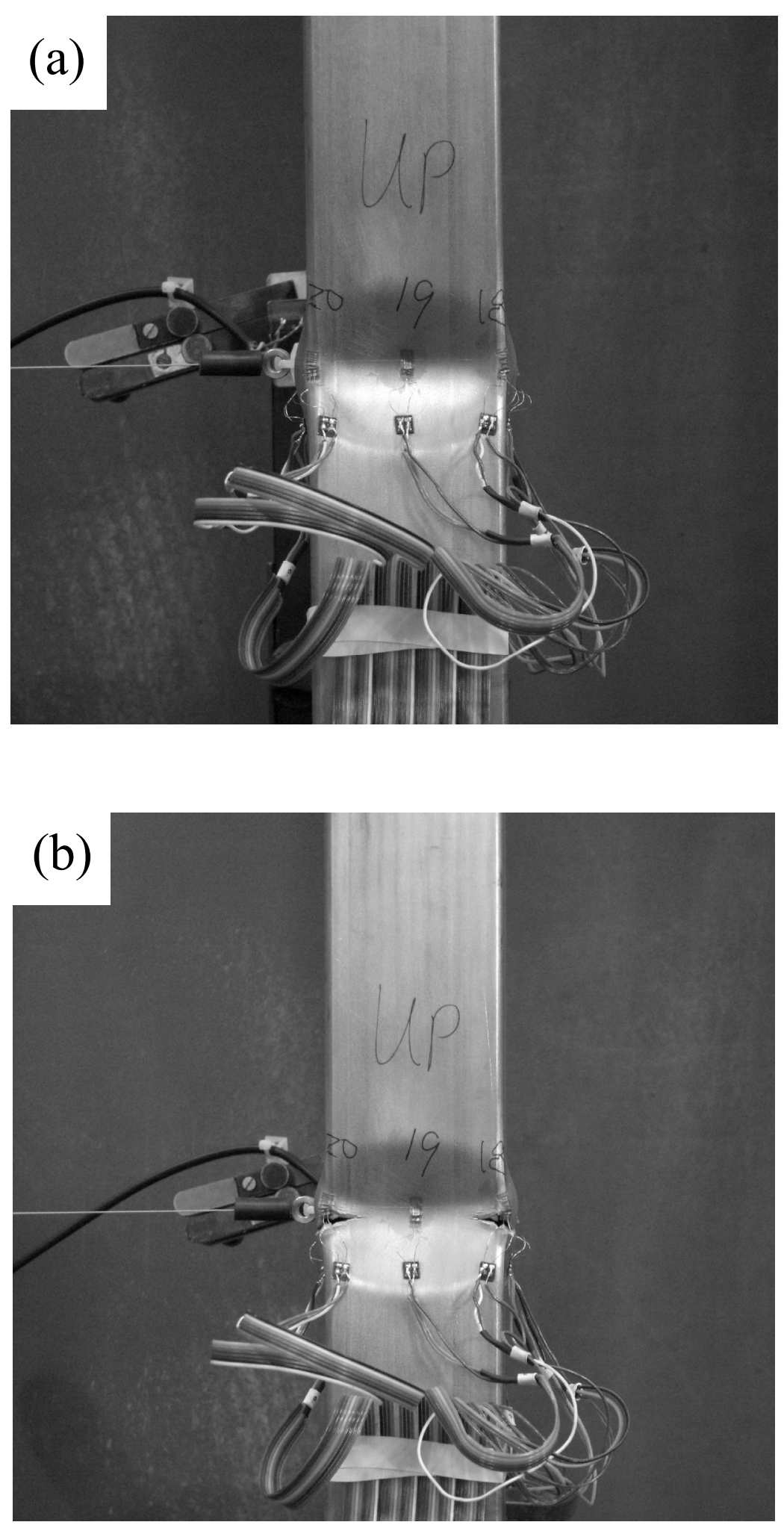


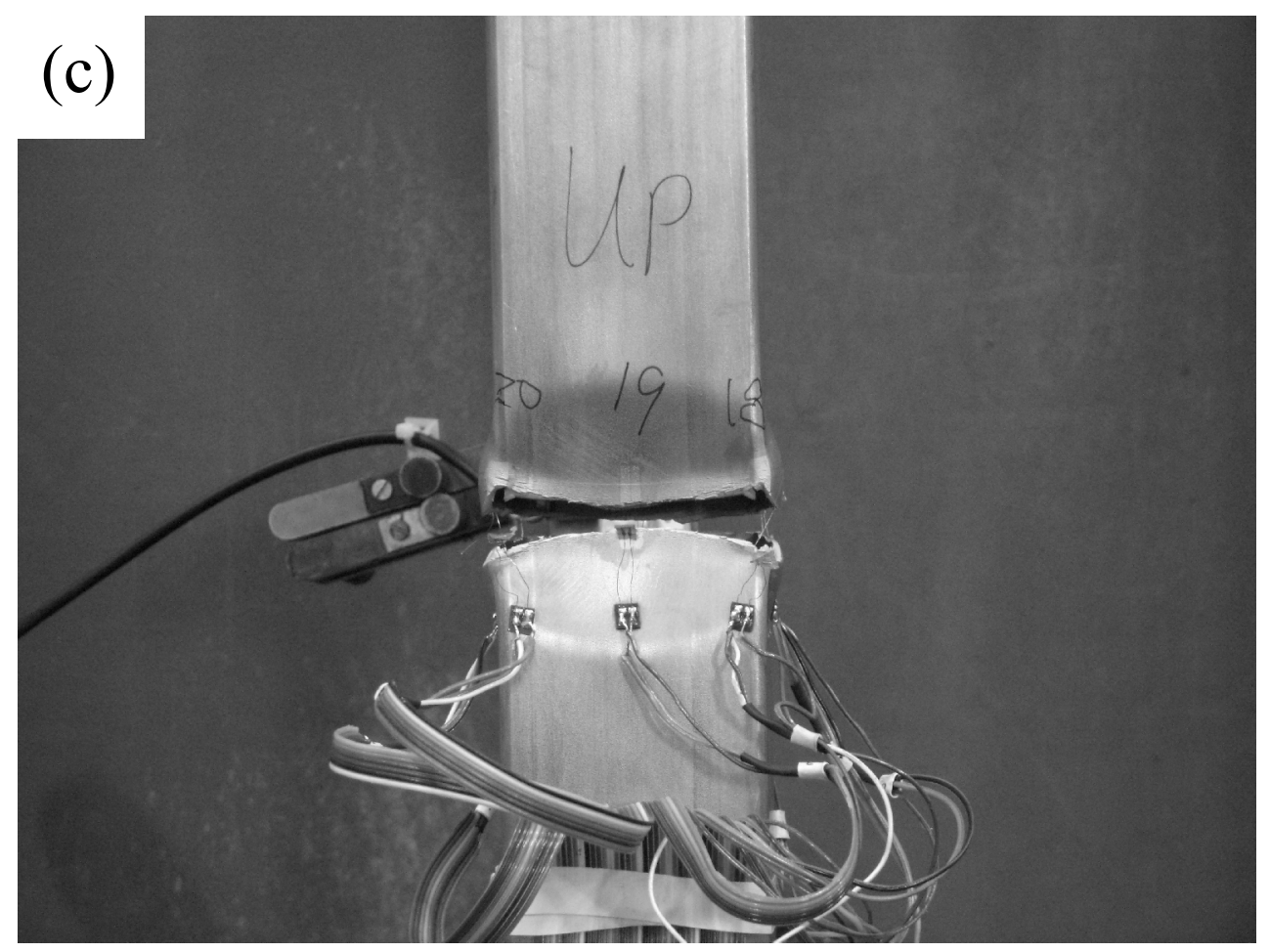

Figs 20(a)-(c): (a) Local buckling, (b) small opening at corners and (c) complete fracture of Specimen $60 \times 40 \times 3 \times 1250$-SS-CF 


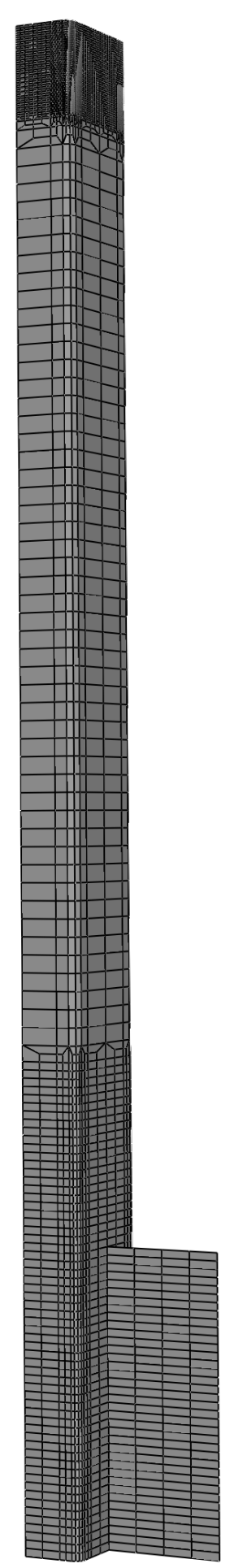

Fig. 21: Model of a quarter of Specimen $50 \times 50 \times 3 \times 1250-$ SS-CF 

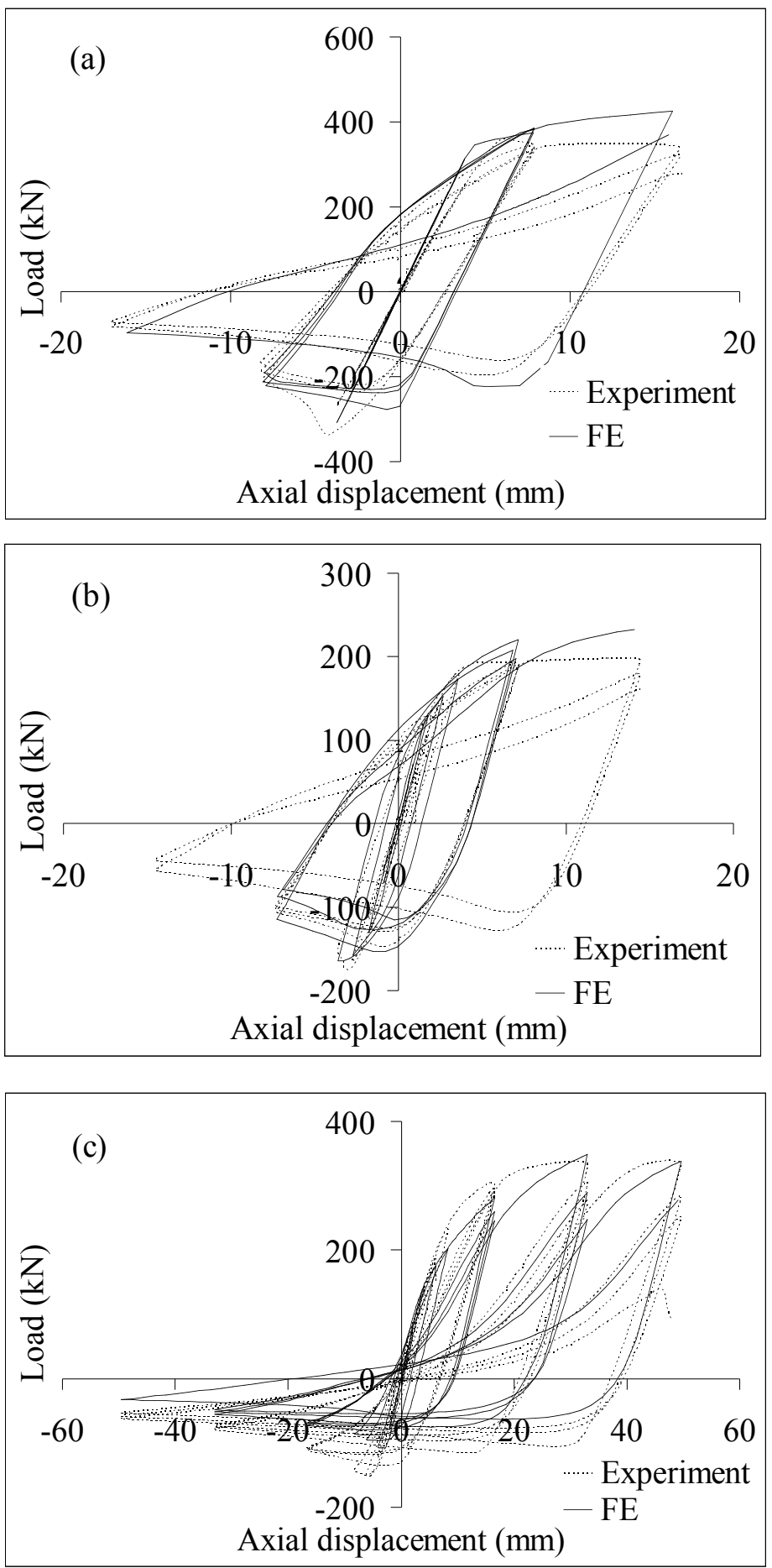

Figs 22(a)-(c): Comparison of hysteretic curves for Specimens (a) $60 \times 60 \times 3 \times 2050$ CS-HR, (b) $40 \times 40 \times 3 \times 1250-\mathrm{CS}-\mathrm{CF}$ and (c) $50 \times 50 \times 3 \times 2850-\mathrm{SS}-\mathrm{CF}$ from FE simulation and experiment 

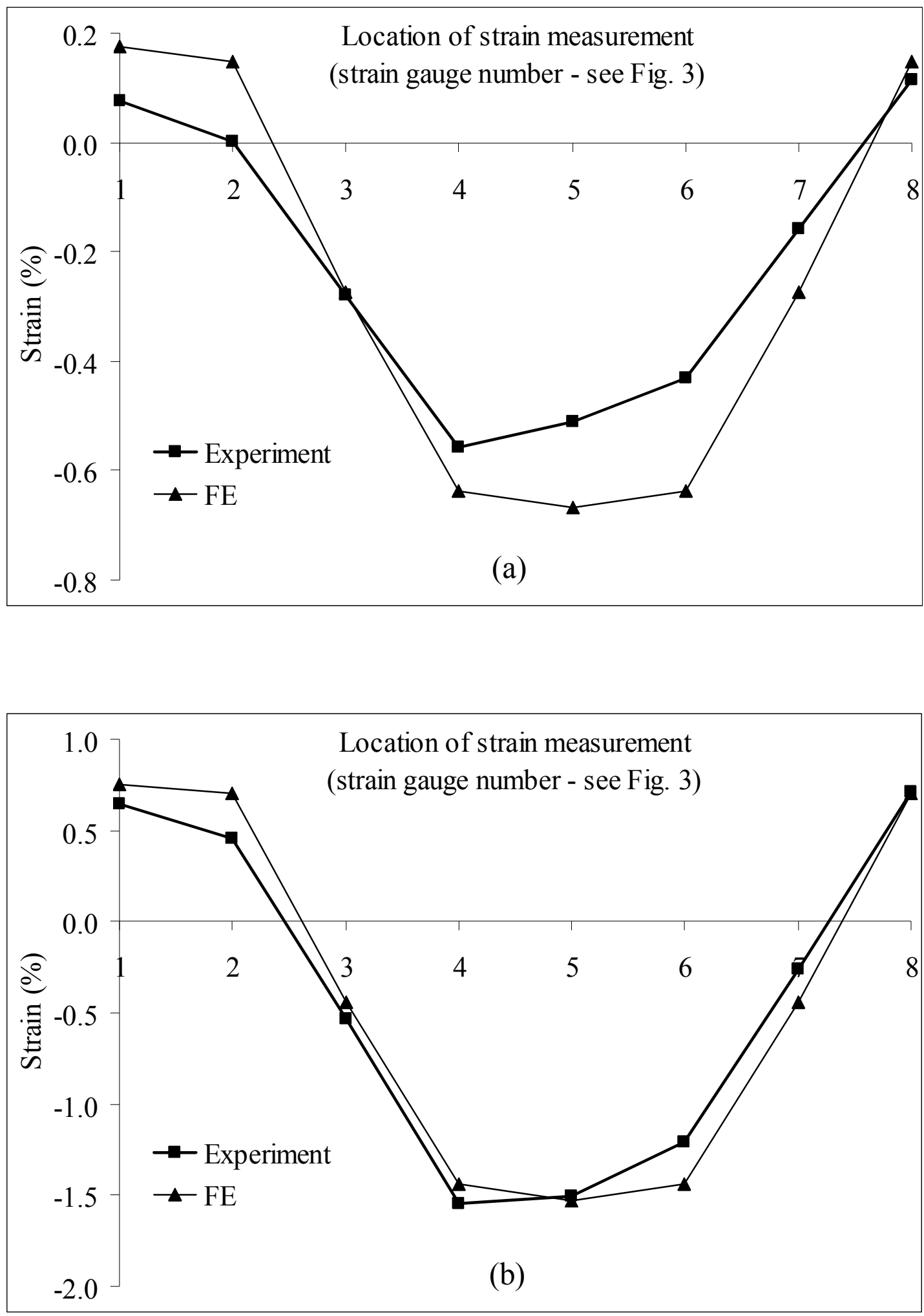


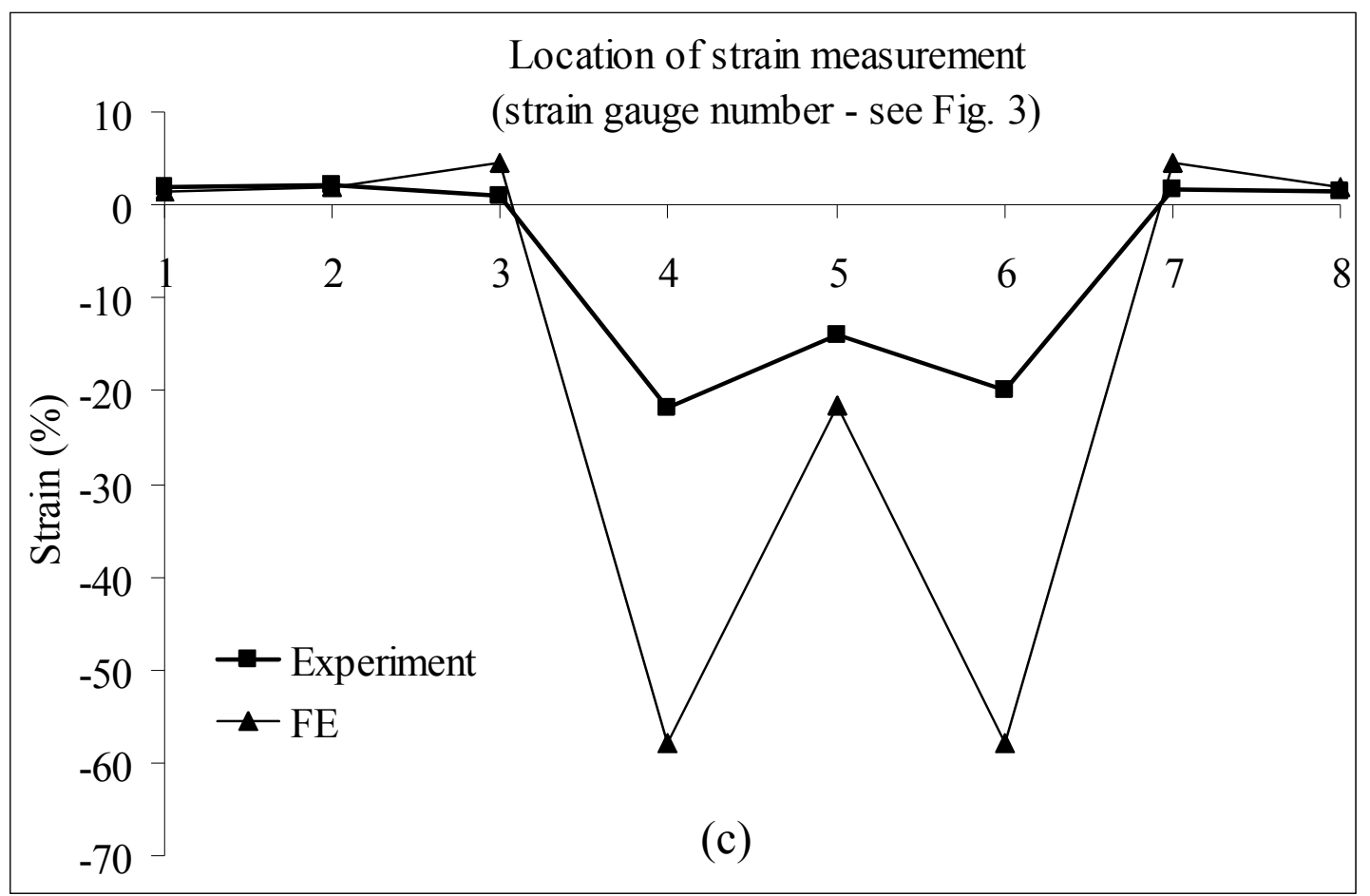

Figs 23(a)-(c): Comparison of strain measurements at mid-length at the maximum compressive displacement in the $4^{\text {th }}, 6^{\text {th }}$ and $8^{\text {th }}$ cycle for Specimen $60 \times 60 \times 3 \times 2850$ SS-CF from FE simulation and experiment 

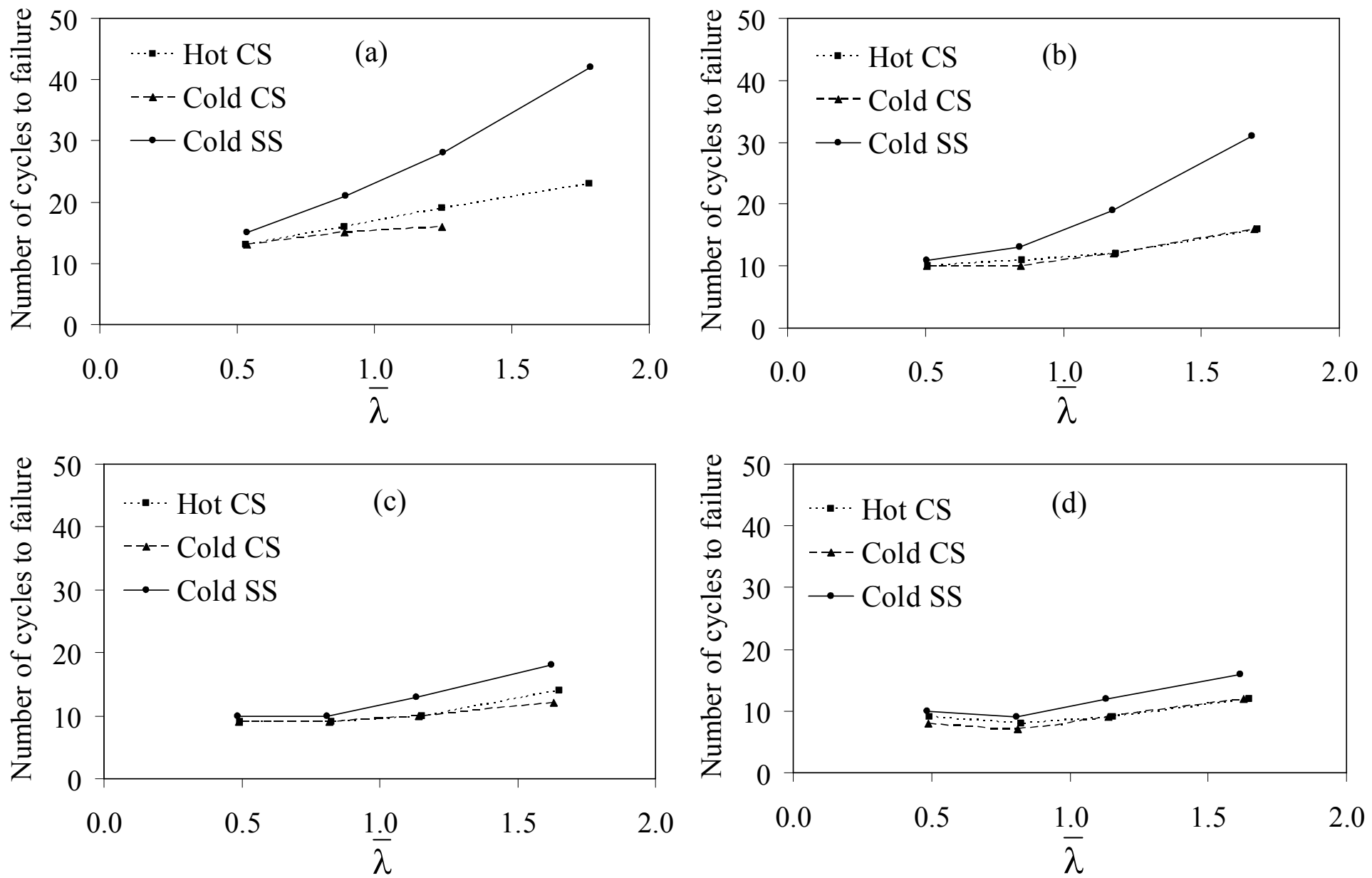

Figs 24(a)-(d): Number of cycles to failure for FE specimens with (a) $6.0 \mathrm{~mm}$, (b) 4.0 $\mathrm{mm}$, (c) $3.0 \mathrm{~mm}$ and (d) $2.5 \mathrm{~mm}$ thick sections 

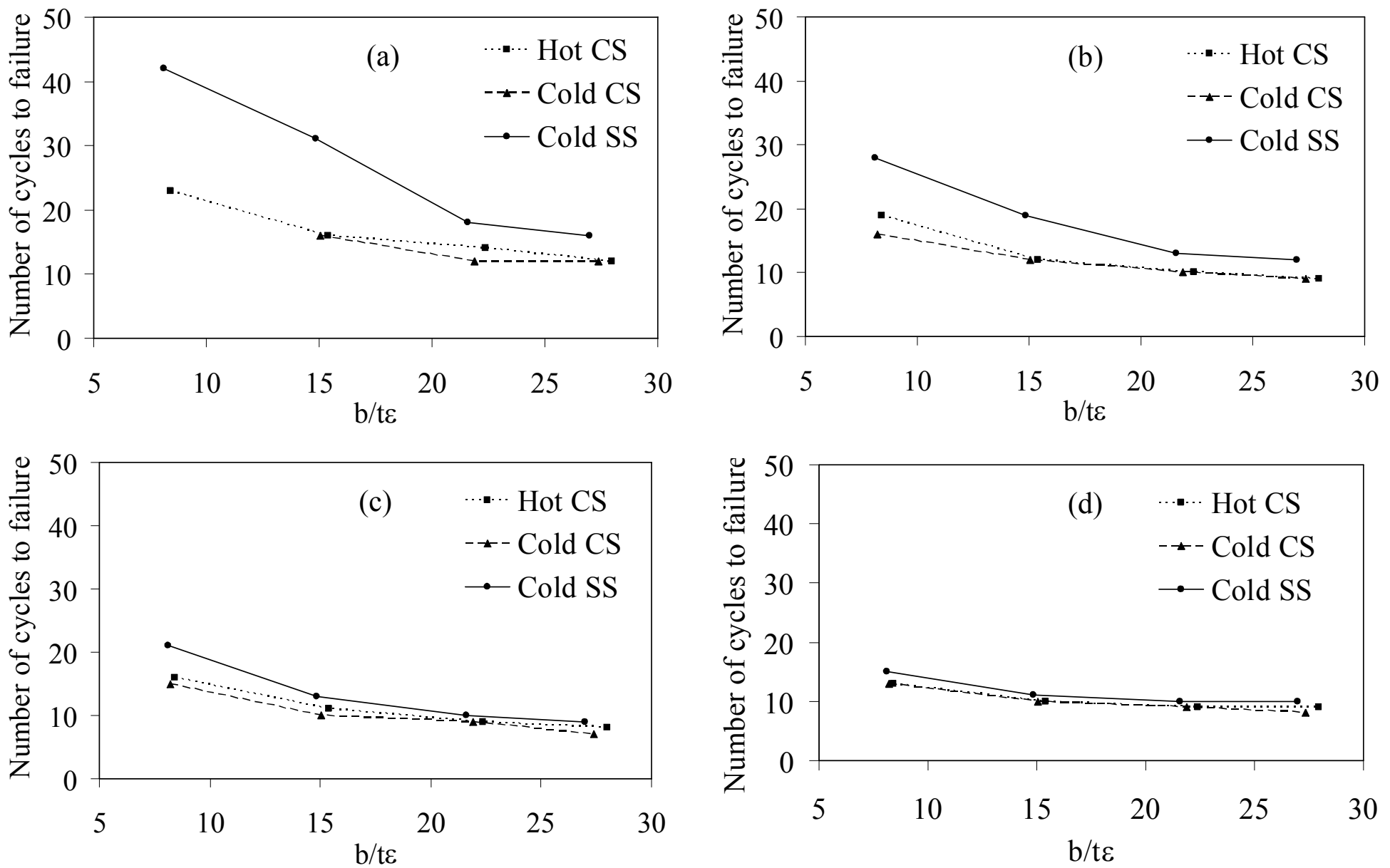

Figs 25(a)-(d): Number of cycles to failure for (a) $5000 \mathrm{~mm}$, (b) $3500 \mathrm{~mm}$, (c) 2500 $\mathrm{mm}$ and (d) $1500 \mathrm{~mm}$ long FE specimens 


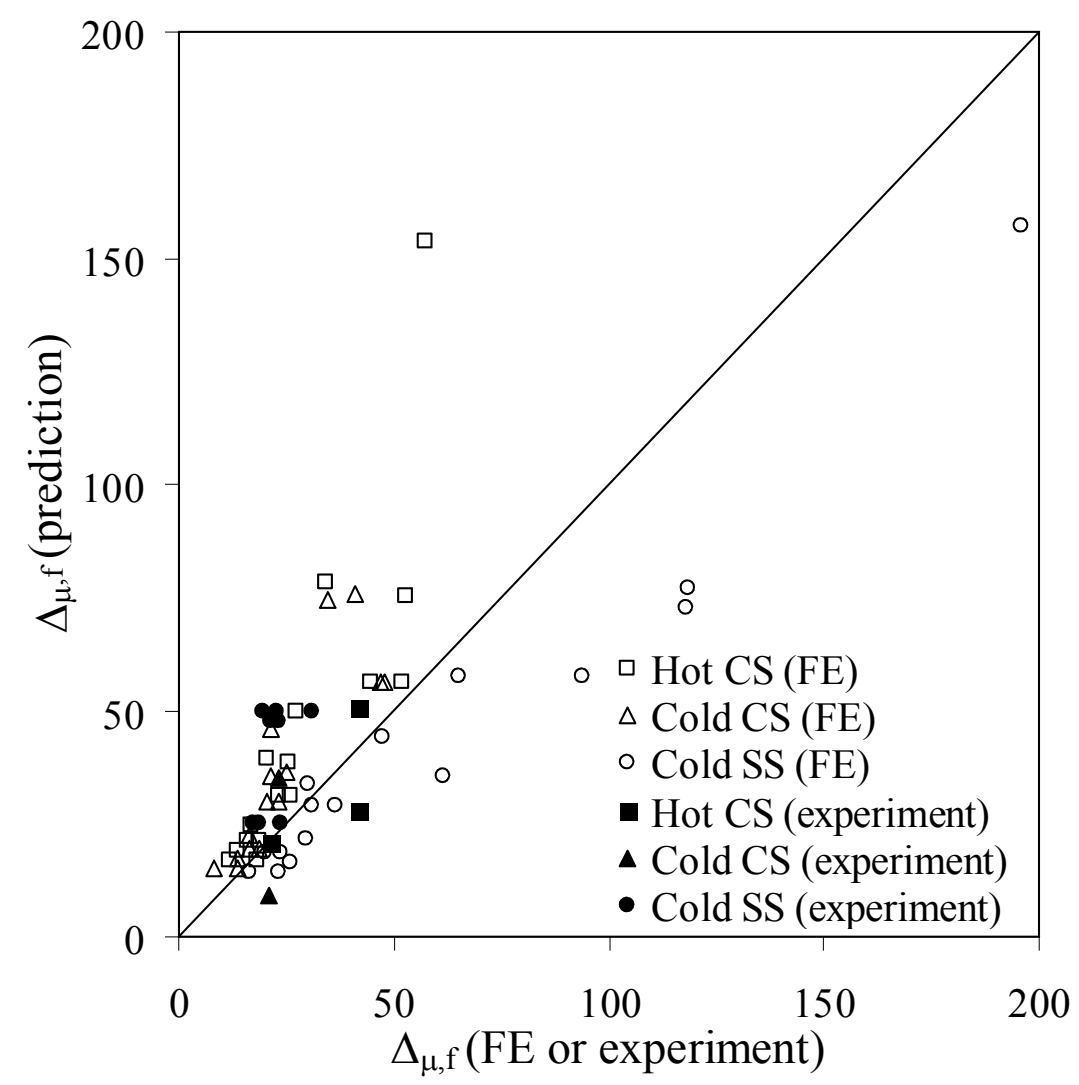

Fig. 26: Comparison between the predicted values of accumulated fracture ductility by Shaback and Brown [8] and the values obtained from FE models and experiments

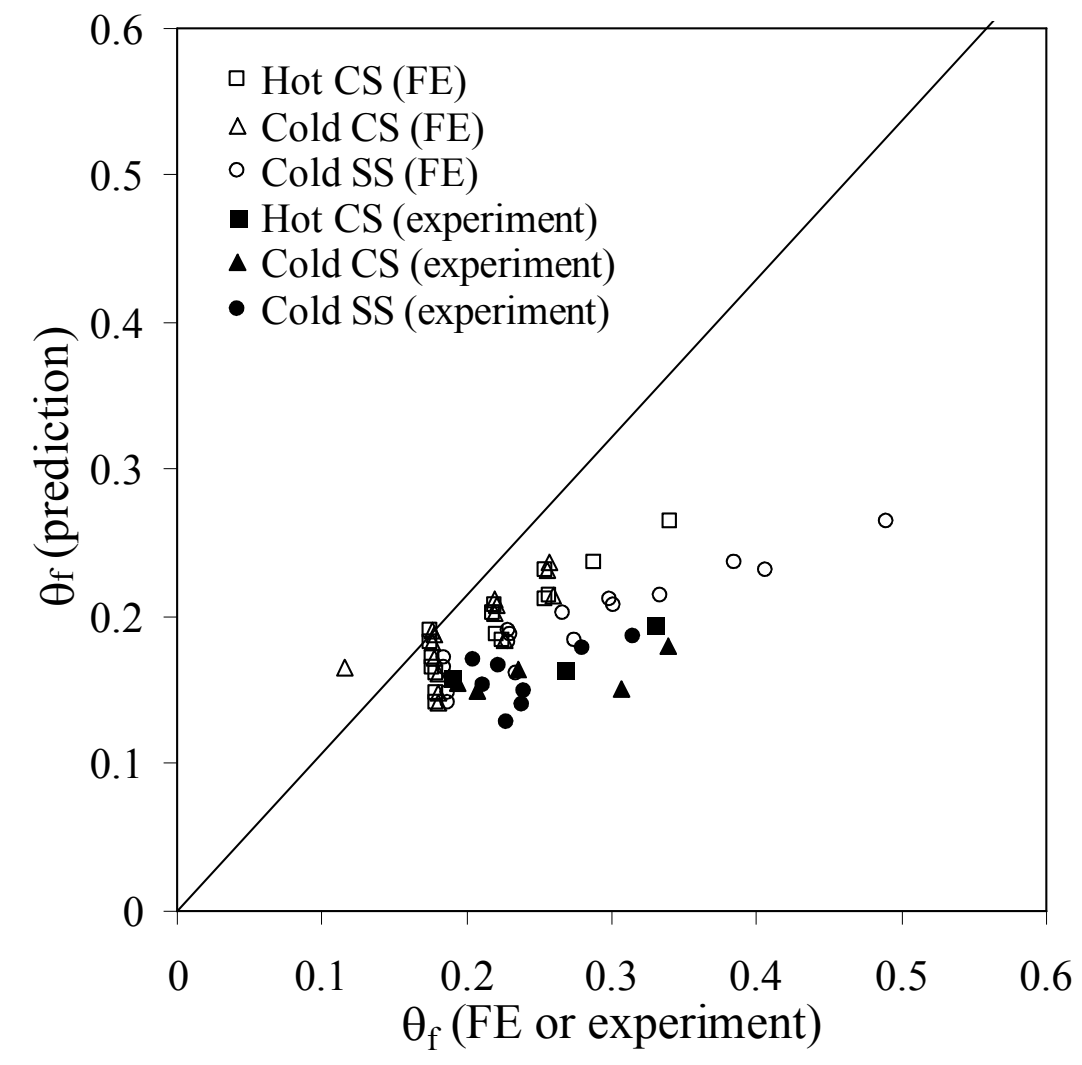

Fig. 27: Comparison between the predicted values of rotation at fracture by Tremblay et al. [34] and the values obtained from FE models and experiments 


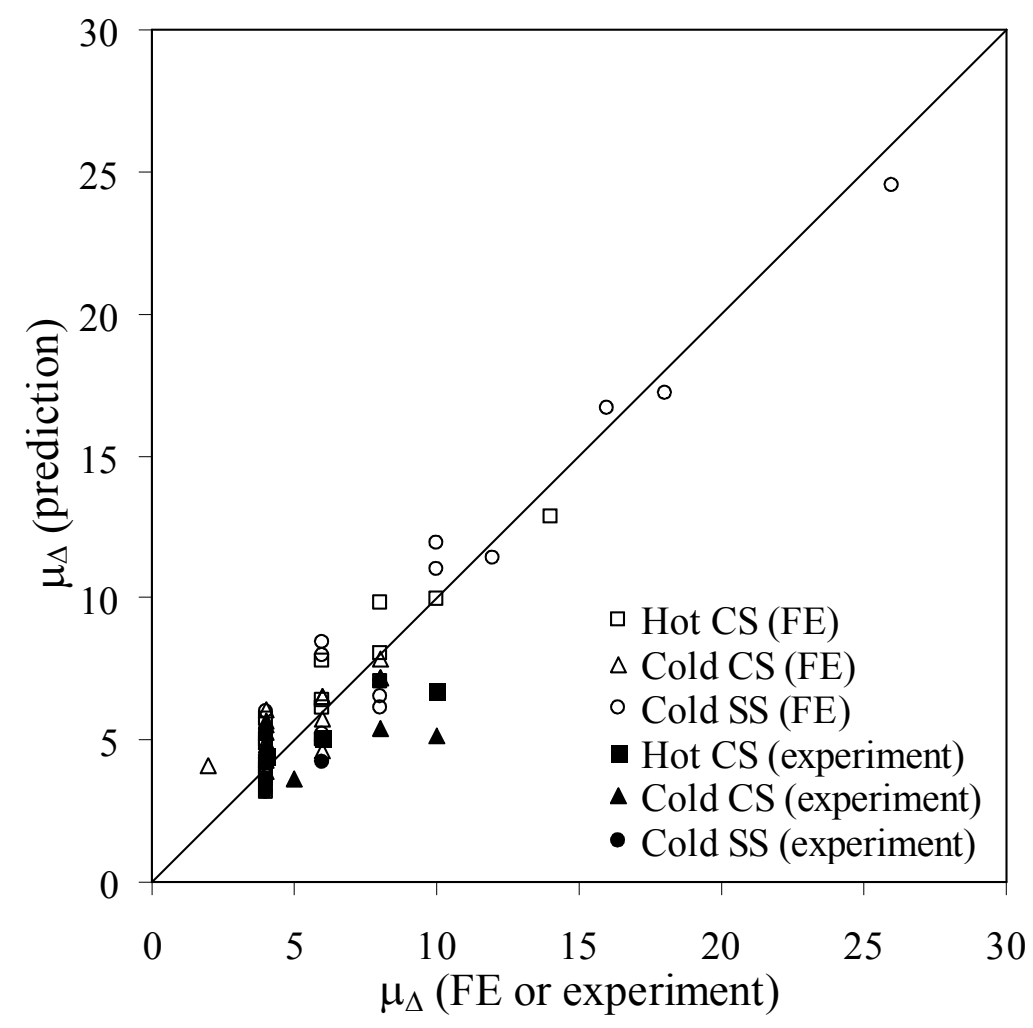

Fig. 28: Comparison between the predicted values of displacement ductility from the proposals in the current study and the values obtained from FE models and experiments

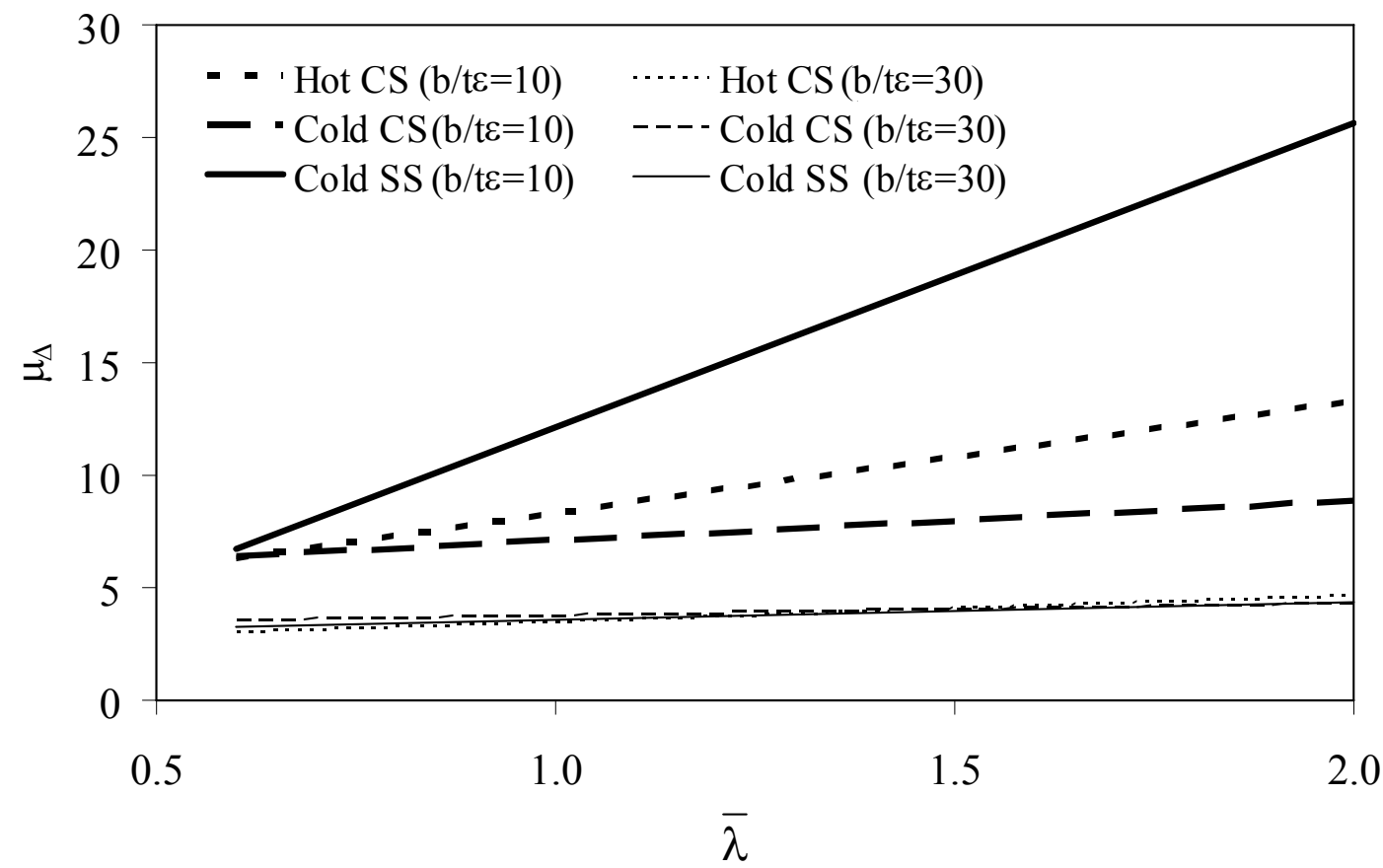

Fig. 29: Variation of displacement ductility against member slenderness of bracing members with cross-section of $b / t \varepsilon=10$ and $b / t \varepsilon=30$ for the three materials 

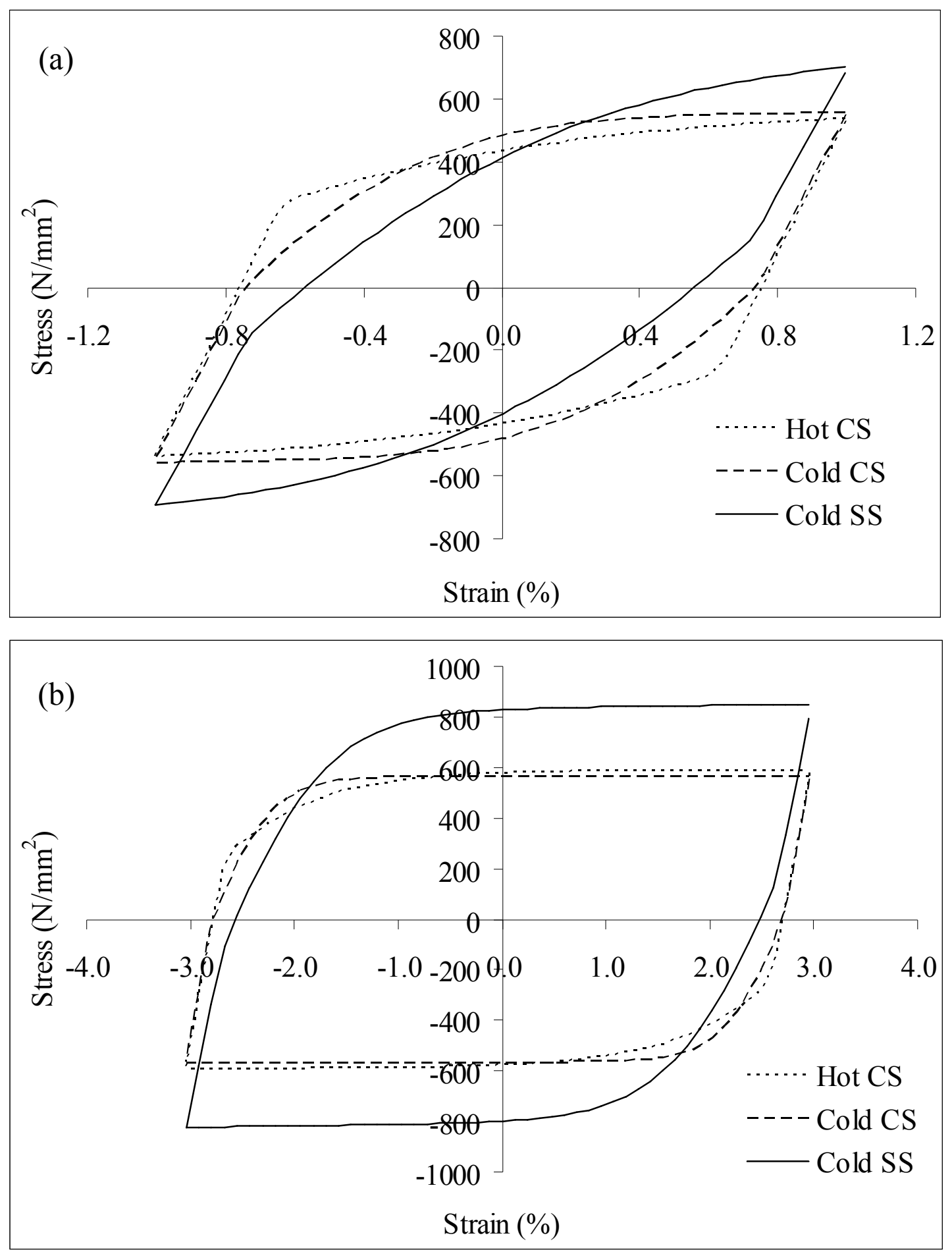

Figs 30(a)-(b): Stress-strain hysteretic behaviour of the three materials subjected to cyclic axial loading at $\pm 1 \%$ and $\pm 3 \%$ strain amplitudes 

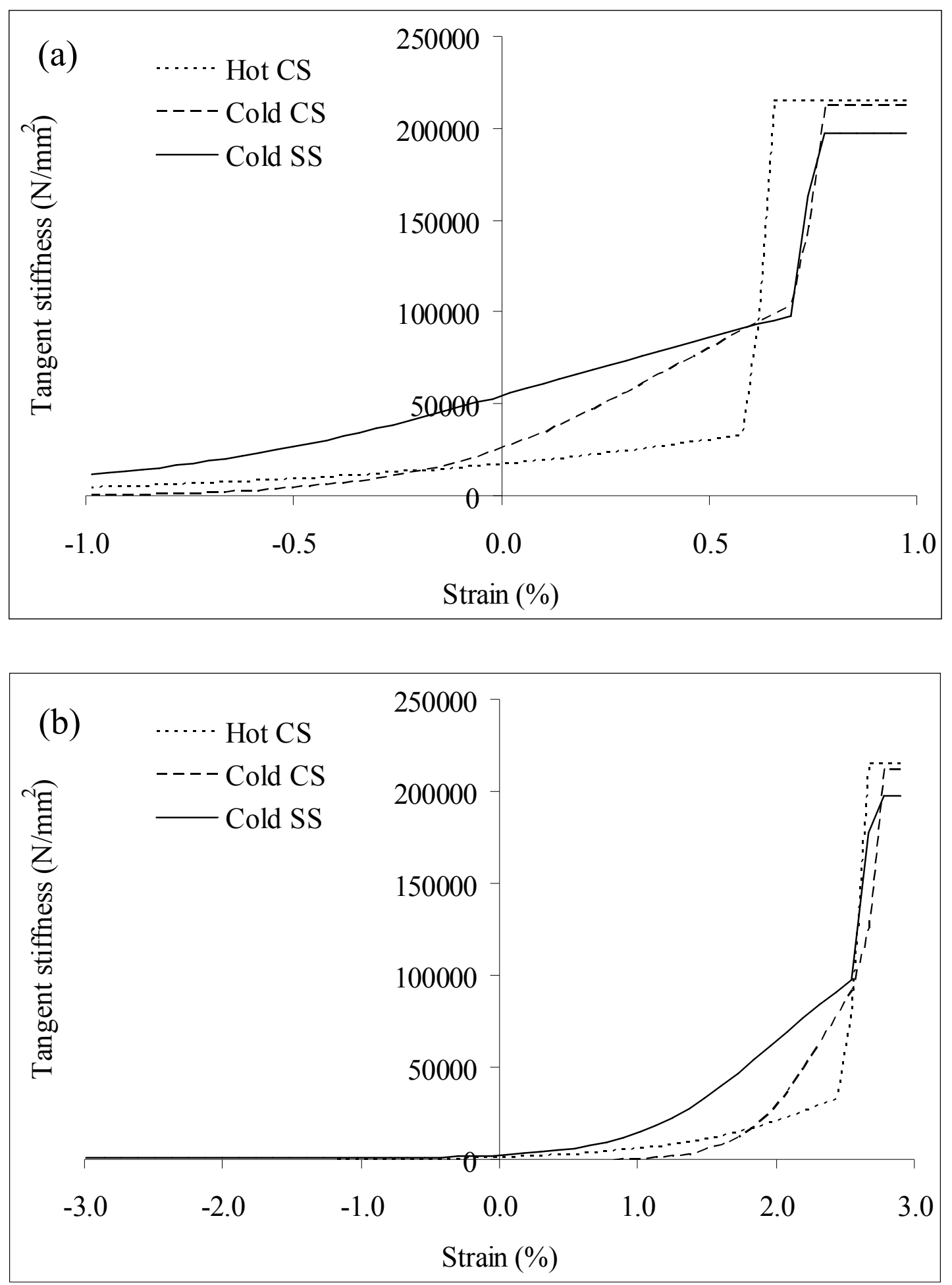

Figs 31(a)-(b): Tangent stiffness of the three materials subjected to cyclic axial loading at $\pm 1 \%$ and $\pm 3 \%$ strain amplitudes 


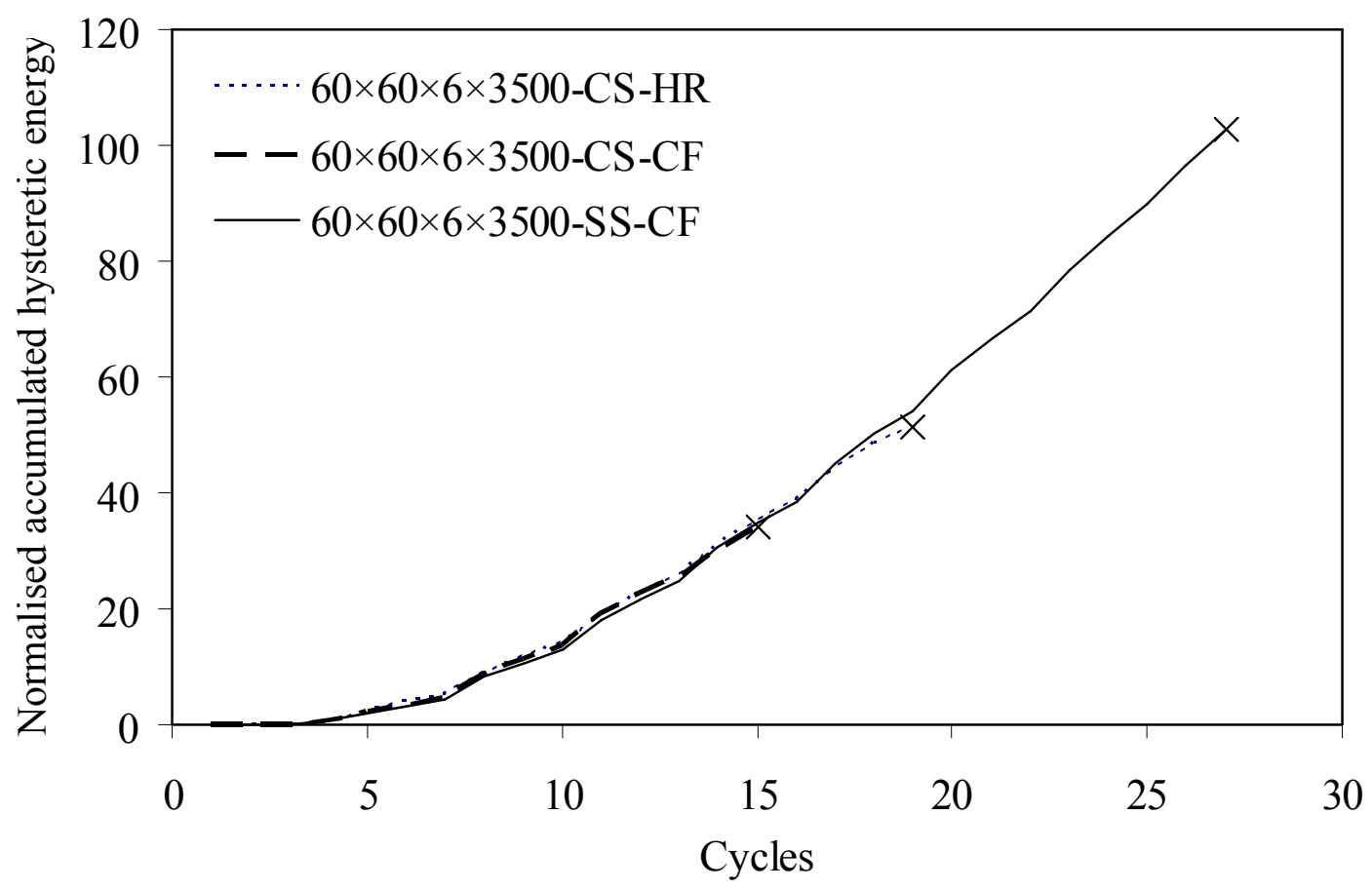

Fig. 32: Normalised accumulated hysteretic energy for $60 \times 60 \times 6 \times 3500$ FE specimens of the three materials 


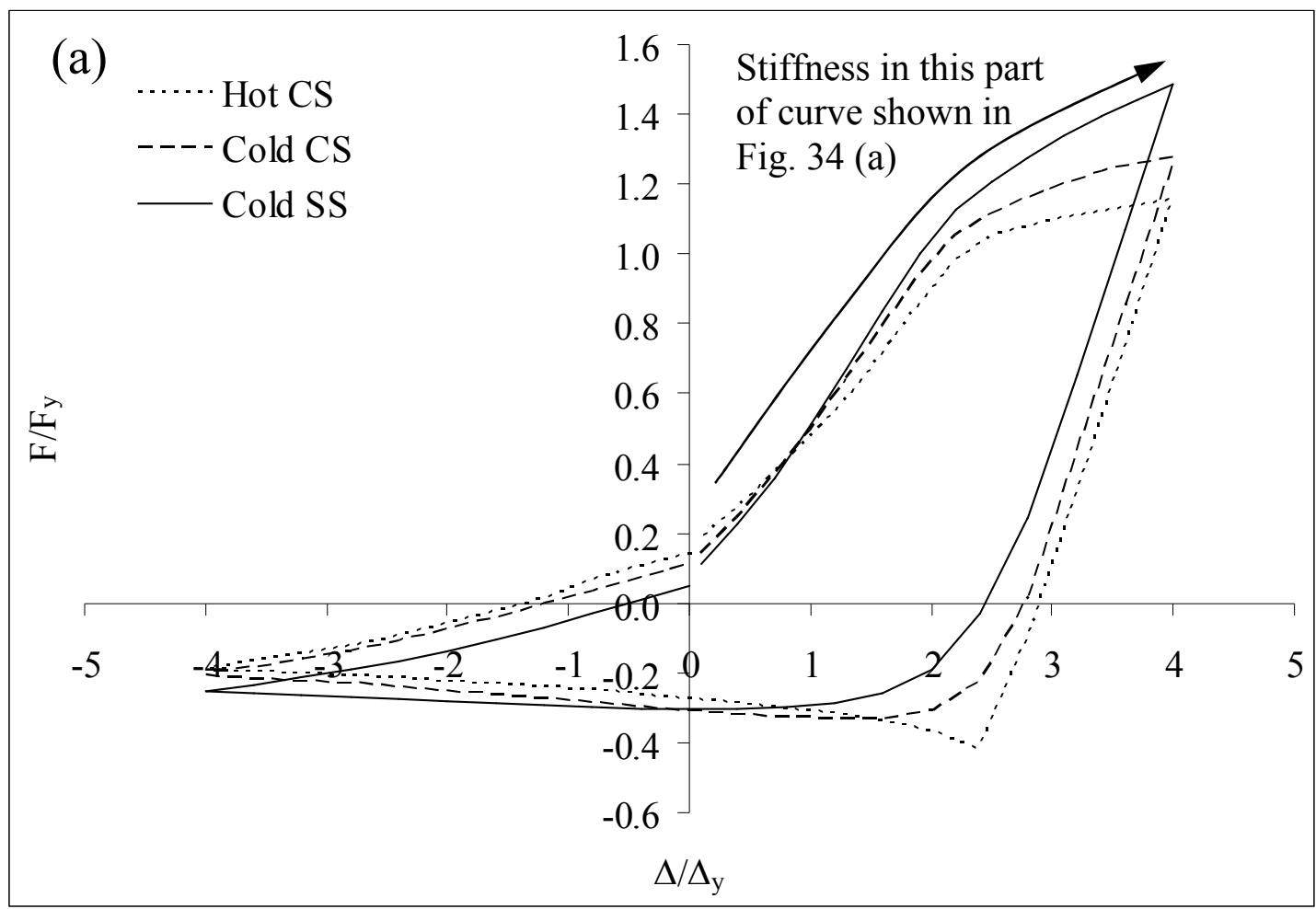

(b)
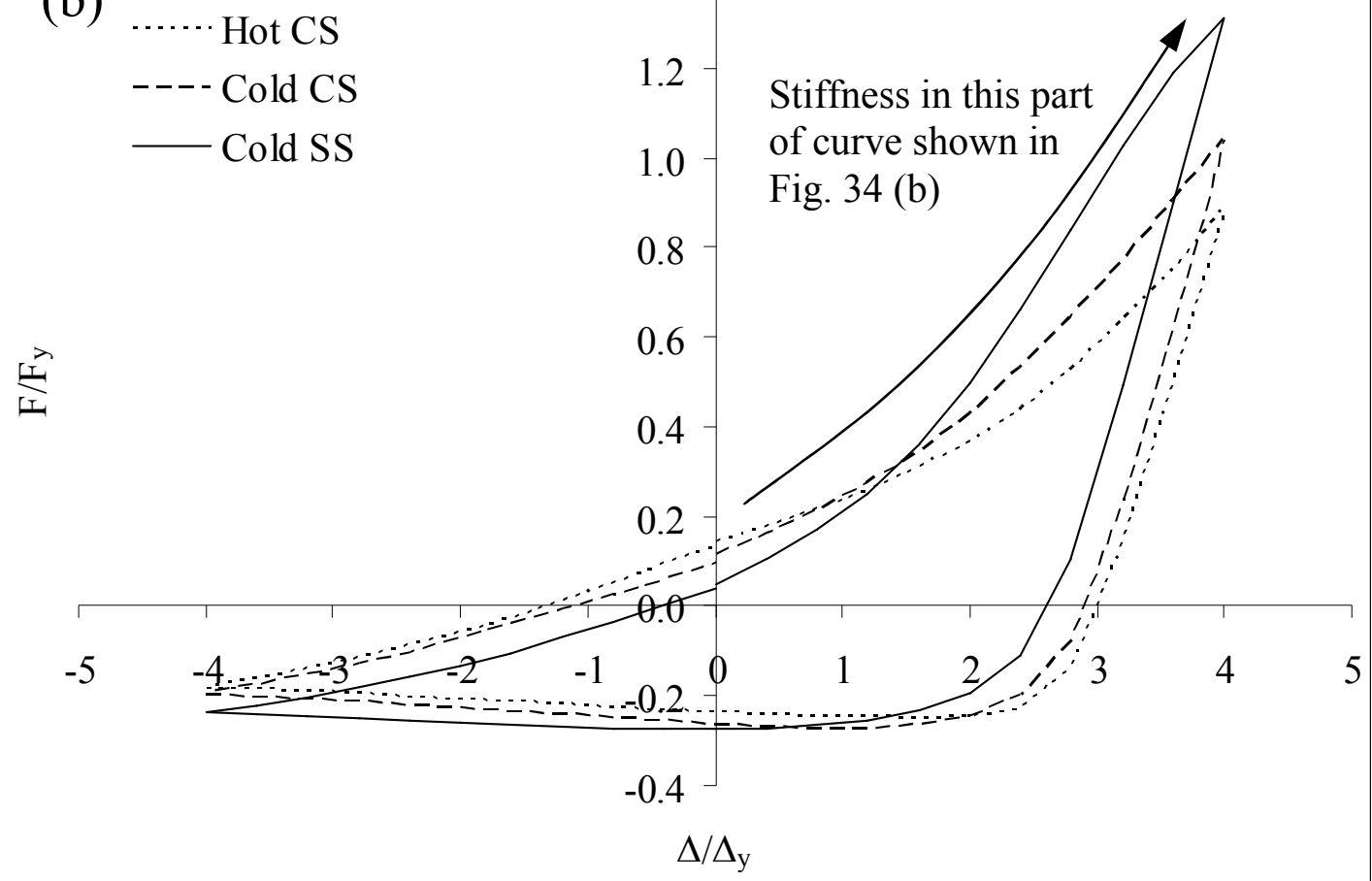

Figs 33(a)-(b): Normalised load-displacement hysteretic loops of the $8^{\text {th }}$ and $9^{\text {th }}$ cycle of $60 \times 60 \times 6 \times 3500$ models of the three materials 

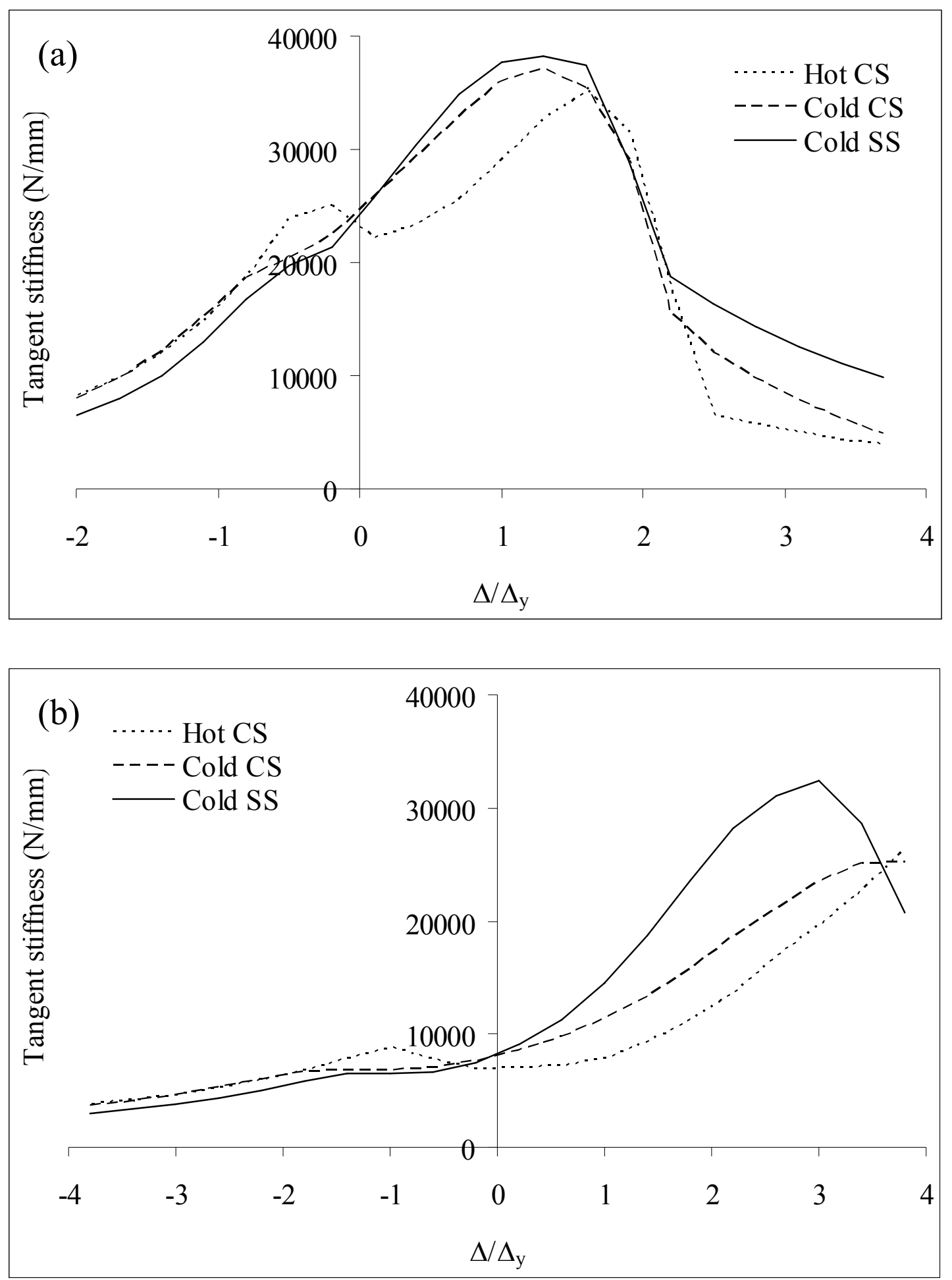

Figs 34(a)-(b): Instantaneous stiffness during the $8^{\text {th }}$ and $9^{\text {th }}$ tensile loading half cycle for $60 \times 60 \times 6 \times 3500 \mathrm{FE}$ specimens of the three materials 